OPEN ACCESS

Edited by:

André Schmidt,

King's College London, UK

Reviewed by:

Frederic Haesebaert,

Centre de recherche de l'Institut Universitaire en Santé Mentale de

Québec, Canada

Andrew James Greenshaw,

University of Alberta, Canada

*Correspondence:

Golnoush Alamian

golnoush.alamian@umontreal.ca

Specialty section:

This article was submitted to Neuroimaging and Stimulation,

a section of the journal

Frontiers in Psychiatry

Received: 30 November 2016 Accepted: 28 February 2017

Published: 17 March 2017

Citation:

Alamian G, Hincapié A-S, Combrisson E, Thiery T, Martel V, Althukov D and Jerbi K (2017)

Alterations of Intrinsic Brain

Connectivity Patterns in Depression and Bipolar Disorders:

A Critical Assessment of

Magnetoencephalography-

Based Evidence.

Front. Psychiatry 8:41

doi: 10.3389/fpsyt.2017.00041

\section{Alterations of Intrinsic Brain Connectivity Patterns in Depression and Bipolar Disorders: A Critical Assessment of Magnetoencephalography- Based Evidence}

\author{
Golnoush Alamian ${ }^{1 \star}$, Ana-Sofía Hincapié ${ }^{1,2,3}$, Etienne Combrisson ${ }^{1,4,5}$, Thomas Thiery $^{1}$, \\ Véronique Martel ${ }^{1}$, Dmitrii Althukov ${ }^{1,6,7}$ and Karim Jerbi ${ }^{1,8}$
}

\begin{abstract}
${ }^{1}$ Department of Psychology, University of Montreal, Montreal, QC, Canada, ${ }^{2}$ Department of Computer Science, Pontificia Universidad Católica de Chile, Santiago de Chile, Chile, ${ }^{3}$ Interdisciplinary Center for Neurosciences, School of Psychology, Pontificia Universidad Católica de Chile, Santiago de Chile, Chile, ${ }^{4}$ Center of Research and Innovation in Sport, Mental Processes and Motor Performance, University Claude Bernard Lyon I, University of Lyon, Villeurbanne, France, ${ }^{5}$ Brain Dynamics and Cognition, Lyon Neuroscience Research Center, INSERM U1028, UMR 5292, University of Lyon, Villeurbanne, France, ${ }^{6}$ Department of Computer Sciences, National Research Institution Higher School of Economics, Moscow, Russia, ${ }^{7}$ MEG Center, Moscow State University of Pedagogics and Education, Moscow, Russia, ${ }^{8}$ Centre de recherche de l'Institut universitaire en santé mentale de Montréal, Montreal, QC, Canada
\end{abstract}

Despite being the object of a thriving field of clinical research, the investigation of intrinsic brain network alterations in psychiatric illnesses is still in its early days. Because the pathological alterations are predominantly probed using functional magnetic resonance imaging (fMRI), many questions about the electrophysiological bases of resting-state alterations in psychiatric disorders, particularly among mood disorder patients, remain unanswered. Alongside important research using electroencephalography (EEG), the specific recent contributions and future promise of magnetoencephalography (MEG) in this field are not fully recognized and valued. Here, we provide a critical review of recent findings from MEG resting-state connectivity within major depressive disorder (MDD) and bipolar disorder (BD). The clinical MEG resting-state results are compared with those previously reported with $\mathrm{AMRI}$ and EEG. Taken together, MEG appears to be a promising but still critically underexploited technique to unravel the neurophysiological mechanisms that mediate abnormal (both hyper- and hypo-) connectivity patterns involved in MDD and $\mathrm{BD}$. In particular, a major strength of MEG is its ability to provide source-space estimations of neuromagnetic long-range rhythmic synchronization at various frequencies (i.e., oscillatory coupling). The reviewed literature highlights the relevance of probing local and interregional rhythmic synchronization to explore the pathophysiological underpinnings of each disorder. However, before we can fully take advantage of MEG connectivity analyses in psychiatry, several limitations inherent to MEG connectivity analyses need to

\footnotetext{
Abbreviations: BD, bipolar disorder; EEG, electroencephalography; fMRI, functional magnetic resonance imaging; MDD, major depressive disorder; MEG, magnetoencephalography; PFC, prefrontal cortex; CEN, central executive network; ACC, anterior cingulate cortex; DBS, deep brain stimulation.
} 
be understood and taken into account. Thus, we also discuss current methodological challenges and outline paths for future research. MEG resting-state studies provide an important window onto perturbed spontaneous oscillatory brain networks and hence supply an important complement to fMRI-based resting-state measurements in psychiatric populations.

Keywords: magnetoencephalography, connectivity, resting-state, psychiatry, depression, bipolar disorder, mental illness, oscillations

\section{INTRODUCTION}

\section{Background}

Over thelast decade, research on the human brain has experienced an important shift in paradigm; the functional investigation of neuronal activity has moved from studying local mechanisms toward large-scale network organization. Unavoidably, this change in the examination of neural connectivity has reached the field of psychiatry. Until recently, most connectivity studies in psychiatric patients were predominantly carried out using functional magnetic resonance imaging (fMRI). The findings from these studies generally indicate the presence of structural and/or functional abnormalities linked to the diseases [e.g., Ref. (1-3)]. Moreover, irregularities are not only observed during cognitive tasks, when subjects are engaged in a sensory, cognitive, or emotional task, but also during rest, when subjects are asked to lay still in the scanner and let their mind wander. The trend in the field of neuroimaging, toward the study of this so-called resting state, has strongly contributed to unveiling intrinsic properties of brain disorders (4-7). Yet many questions about the neurophysiological bases of resting-state alterations remain unanswered.

A parallel stream of research explores the physical connections between brain regions by assessing structural connectivity with magnetic resonance imaging (MRI) using diffusion tensor imaging (DTI) and fractional anisotropy. These techniques allow the examination of white matter integrity and fiber tract organization and are thereby able to reveal anatomical disruptions of long-range structural connections (8). However, DTI is principally useful for pathologies for which we know of preexisting structural anomalies and less so for illnesses without obvious disruptions in connectivity $(4,9)$. Furthermore, although fMRI is promising for the investigation of the spatial organization of the cortex, it is limited by its temporal resolution and by the fact that it is an indirect measure of neural activity. Moreover, because it measures the brain's hemodynamic responses, fMRI is useful to study slow activity fluctuations (i.e., $<0.1 \mathrm{~Hz}$ ), but is unable to capture brain activity patterns at higher frequencies. Consequently, neuroimaging methodological developments and studies of the past 10 years have been reflective of the scientific community's appreciation of the importance of electrophysiology for our understanding of network connectivity $(10,11)$. This change is portrayed by the flux in research employing electroencephalography (EEG), intracranial electroencephalography (iEEG), and magnetoencephalography (MEG), three tools with excellent temporal resolution. Specifically, a spotlight has been shined on the behavior of local and long-range synchronized brain oscillations in healthy cognition and, also, as potential markers for altered neural connectivity in (psychiatric) diseases (12-15).

When small neighboring neuronal populations synchronize their oscillations, local assemblies are forged, and coupling among these small assemblies can bridge distant areas (creating longrange connections) (10). Disruptions in this mechanism could unravel a number of neuropathologies and psychopathologies. Neuronal synchronizations are thought to operate on short-time scales, and changes in spectral power are optimally detectable by electrophysiological recordings. Thus, we can examine neural network connectivity patterns by measuring the electrophysiological activity of two or more brain regions of interest (ROIs) using EEG, iEEG, or MEG (16). Of increasing interest, MEG (17) has emerged as a valuable, non-invasive tool to assess local and long-range modulations of synchronized neural activity in humans [e.g., Ref. (14, 18-24)].

Although EEG permits the probing of large-scale networks, with high temporal resolution, MEG has a number of advantages. For instance, the magnetic signal that is captured by MEG is less distorted by brain tissue and skull than the electrical field detected by EEG. In addition, MEG source reconstruction methods can provide valuable spatial information to better characterize neural network modulations. Finally, in the context of clinical research, and more specifically in psychiatry, the fast and easy setup of the MEG system is likely to be less unnerving for patients than the lengthy procedure of EEG. Taken together, exploration of the potential of MEG in psychiatry is an important endeavor that could lead to better understanding of psychopathology. Further details about the technical aspects of MEG have been overviewed elsewhere [e.g., Ref. (18, 20, 23, 25)].

\section{Purpose of This Review}

Despite being the object of a thriving field of clinical research, the investigation of intrinsic neural network alterations in psychiatric illnesses is in its early days and is predominantly conducted using fMRI or EEG. The recent contributions and future promise of MEG in this field are not fully recognized and valued. In this article, we review recent findings in MEG resting-state connectivity within two mood disorders: major depressive disorder (MDD) and bipolar disorder (BD). Most importantly, this review provides a critical assessment of currently employed methods and outlines important limitations that need to be considered in future resting-state MEG studies of mood disorders. 


\section{Important Concepts and Terminology Resting-State Networks}

When subjects are asked to lay or sit still in an MRI, PET, EEG, or MEG setup and to let their minds wander, the activity that arises is one that speaks of the fundamental organization-or disorganization-of the brain [e.g., Ref. (26-29)]. Resting states can be categorized into several networks (on the order of $7 \pm 1$ ): the sensorimotor network, the primary and extrastriate visual network, the auditory network, lateralized frontoparietal networks, the temporoparietal network, the central executive network (CEN), and the, most extensively studied, default mode network (DMN) (27, 30-35). The DMN englobes primarily the medial prefrontal cortex ( $\mathrm{mPFC}$ ), the posterior cingulate cortex, and the precuneus cortex, as well as the inferior parietal cortex, the lateral temporal cortex, and the subgenual anterior cingulate cortex (ACC) $(27,34)$. A large amount of evidence shows the $\mathrm{DMN}$ to be deactivated when one is engaged in a cognitive or sensorimotor task and active during rest or meditative tasks (7, 36-39). Of particular interest, disruptions in this network have been linked to the occurrence of psychopathological symptoms (e.g., depressive, manic, or psychotic episodes) $(27,34,40-42)$.

\section{Anatomical, Functional, and Effective Connectivity}

The literature on neural network connectivity, particularly graph theory, suggests that the purpose of a node is guided by how it is connected to other nodes in a given network and that its function is a consequence of the action of its integral network (43). Hence, when resting-state activity is observed for a few minutes, the spontaneous oscillatory behaviors form consistent and reliable functional networks [e.g., Ref. (44)]. The efficiency of the connections within and between these networks appears to rely on at least two main factors: epigenetics and experience (45). The first factor pertains to the interaction between genes and the growth of brain structures, whereas the second pertains to intrinsic neural activity and activity-dependent changes in synaptic strength (e.g., learning) elicited by a person's interaction with their environment.

Three types of connectivity are generally examined: anatomical, functional, and effective. First, anatomical connectivity pertains to the physical connection between brain regions. It is typically examined using MRI-based DTI analysis of white matter, axonal, and tracts (46). Second, functional connectivity is used to describe the statistical dependency of time-series activity arising from two brain areas $(9,47,48)$. It can be measured using linear and non-linear tools such as correlations, coherence, phase-lag index, and mutual information (49-52). It is important to note that although evidence from both human and animal studies shows a close relationship between structural and functional connectivity $(5,53-55)$, direct anatomical linkage is not necessary for functional connections to take place $(54,56)$. Finally, effective connectivity speaks of the direct or indirect influence of one brain system on another based on neuronal coupling $(9,44)$ and can be measured using metrics such as Granger causality and direct transfer functions (57).

In this review, we focus on functional connectivity abnormalities across MDD and BD.

\section{Local Power Modulations vs Long-Range Interareal Connectivity in MEG and EEG}

It has been proposed that local and long-range neural synchrony patterns speak of the inherent organization of the brain $(43,58)$, and thus, an exploration of oscillatory rhythms could help us understand the fundamental neural functioning of different populations. However, confusion can emerge for investigators who are new to the discussion on neural network connectivity. This confusion is entangled in the lack of consistency in the vocabulary employed to describe the two different processes of local and long-range synchrony. It has been argued that when neural populations synchronize, it is a phenomenon that expands across multiple temporal and spatial scales, from local integration of information within the areas that specialize in the same functions to long-range connections that connect different modalities of an object (10). Generally speaking, local synchrony is what is captured by power estimation from a single brain signal (e.g., data from one channel or cortical source). By contrast, long-distance synchrony is captured by estimating the coupling between data from two brain signals.

Specifically, local power modulations of a neural population reflect the activity of a small spatial area of neurons on the order of $1 \mathrm{~cm}$ [based on experiments in visual networks, e.g., Ref. (59)]. The measure of spectral power is taken as a reflection of the amplitude of oscillations at different frequencies (60). Neurophysiological studies have underlined the importance of examining local synchronization to observe the different types of information that are carried by different frequency bands $(10,61)$. As for long-range connectivity, it reflects the functional coordination and synchronization of time series from two brain regions that may or may not have direct structural linkage (e.g., through myelinated white matter tracts). This type of connectivity bridges brain areas between and within different neural networks $(43,58$, 60, 62).

Although both local and long-range synchrony can be measured at sensor and source levels during EEG and MEG studies, caution should be taken when measuring the statistical or coherence differences between two recording (sensor) sites. Indeed, what may first be thought to be coordinated time series reflecting connectivity between two brain areas (63) may in fact be spurious coupling arising from volume conduction or field spread [e.g., Ref. $(48,64)]$. Different methods have been proposed to overcome this challenge. A solution that can be applied to reduce the impact of this linear mixing limitation is to use coupling measures that are not overly affected by field spread and perform the connectivity estimations in MEG source space [cf Ref. $(48,52,65,66)$ ] [see Contrasting Controls and Patients: Differences in Artifacts and Signal-to-Noise Ratio (SNR)].

\section{ABNORMAL CONNECTIVITY IN PSYCHIATRIC DISORDERS: WHERE DO WE STAND?}

The following section provides a brief and non-exhaustive multimodal overview of the rapidly increasing body of neuroimaging research that links psychiatric disorders with pathological 
alterations in neuronal connectivity, in line with previous work that overviewed network connectivity in SZ $(60,67)$ and depressed patients (34) across different neuroimaging modalities. Because of the current effervescent nature of this field, an in-depth account of the neuronal network dysfunction in mental illness is beyond the scope of this review. Instead, we will focus on findings that are particularly relevant to past, current, and potentially future resting-state MEG investigations. With this in mind, we first describe recent resting-state EEG and fMRI evidence that suggests dysfunctional intrinsic neural communication in MDD and $\mathrm{BD}$.

\section{Major Depressive Disorder}

With over 100,000 scientific papers on PubMed, depression is the most common and the most studied psychiatric illness in humans. MDD is characterized by features such as low mood and/or a loss of interest in daily activities for an extended amount of time and, typically, involves ruminative, self-referential thoughts (68). A lifetime prevalence of $11.3 \%$ has been reported in Canada (69) and $16.2 \%$ in the United States (70), whereas across the world, it is estimated that 350 million individuals suffer from depression (71).

Although a number of impactful task-based studies have explored alterations in oscillatory synchronizations [e.g., Ref. (72-74)], the following subsections will focus on resting-state fMRI and EEG studies in MDD population.

\section{fMRI Resting-State Connectivity Findings in MDD}

Given the DMN's role in self-referential behaviors $(7,27)$, this network, particularly the $\mathrm{mPFC}$, is recurrently noted as a region important for the discrimination of depression from normal population $(34,75-77)$. Specifically, fMRI studies show depressed patients to display increased connectivity between certain nodes of the DMN [for instance, between the subgenual ACC and the posterior cingulate cortex (78)], which could be detrimental to cognitive processes $(4,79)$. These findings are supported by reviews that also highlight enhanced patterns of connectivity within these areas of the $\operatorname{DMN}(3,80)$. In addition, studies have observed altered connectivity between nodes of the DMN and the nodes of the CEN. For instance, one study found enhanced connectivity between the dorsolateral prefrontal cortex (PFC) and the subgenual ACC (81), whereas a review found decreased connectivity between the inferior/superior parietal DMN and dorsal CEN (3).

Moreover, a number of original studies and reviews have reported atypical functional connectivity within areas key to emotional processing. Indeed, limbic regions [amygdala, insula $(82,83)]$, parts of the DMN $[\mathrm{mPFC}(77,83)]$, and long-range connections between the DMN and the limbic system [e.g., thalamus and posterior cingulate cortex (79)], as well the CEN and the limbic system [e.g., dorsolateral PFC and amygdala (84-86)], appear reduced in patients compared to controls. However, connectivity between the saliency network (i.e., anterior insula, dorsal ACC) and the anterior DMN (34), as well as between the insula and the amygdala (87) seems enhanced in depressed individuals when compared with controls.
All in all, within and between network connectivity of the DMN and limbic system appear to be altered in MDD patients, particularly with respect to projections involving the subgenual ACC. The atypical resting-state organization of their brain appears to correlate with their cognitive and emotional symptoms (88).

\section{EEG Resting-State Connectivity Findings in MDD EEG Power Modulations (Local Synchronization)}

Examinations of local synchronizations in depressed populations have consistently found low-frequency bands $(<20 \mathrm{~Hz})$ to display enhanced power and coherence across most brain regions (3, 89-93). However, power modulations in higher frequency band $(>30 \mathrm{~Hz})$ do not seem to be a discriminative factor to differentiate the resting-state of depressed and control subjects [e.g., Ref. (3)].

\section{EEG Connectivity (Long-Range Synchronization)}

Similar to the findings from fMRI, EEG studies have found disruptions and asymmetrical connectivity patterns within the frontal lobe of MDD patients in theta $(5-7 \mathrm{~Hz})$ and alpha (8-13 Hz) frequency bands compared with healthy control subjects $(94,95)$. Treatment-based EEG studies established once more the importance of the subgenual ACC. Indeed, depressed patients appear to show enhanced connectivity within nodes of the DMN and between nodes of the DMN and the CEN (3, 92). Specifically, enhanced connectivity in alpha frequency band $(8-12 \mathrm{~Hz})$ between the subgenual ACC and left mPFC is observed before antidepressant treatment, which switched into enhanced connectivity in beta frequency band $(12.5-20 \mathrm{~Hz})$ between the subgenual ACC and right mPFC after antidepressant treatment, thus underlying the recurrent asymmetrical connectivity patterns observed in MDD patients' frontal lobe $(92,95)$. Moreover, it has been suggested that alterations in frontotemporal connectivity in delta/theta $(1-8 \mathrm{~Hz})$ frequency range could be used a marker to predict responders and non-responders to antidepressant medication (i.e., selective serotonin reuptake inhibitor), with hyperconnectivity between these areas being associated to poorer response (96).

The observations discussed above are consistent with insights achieved using deep brain stimulation (DBS) in MDD patients. Clinical trials with DBS have targeted the overactive subgenual ACC and the thalamocortical pathway, for the treatment of severe depression $(97,98)$. Although the success of such surgical procedure is still debated [(99-103)], DBS involves the implantation of intracranial electrodes that allow a rare window into the circuitry of MDD.

\section{Bipolar Disorder}

Bipolar disorder is a functionally debilitating disorder. The main categories of $\mathrm{BD}$ are $\mathrm{BD}-\mathrm{I}$ and $\mathrm{BD}-\mathrm{II}$, which are characterized by a combination of manic episodes and depression and by hypomania episode(s) and depressive symptoms, respectively (68). A lifetime prevalence of $2.6 \%$ has been reported in Canada (69) and around 4\% (across all types of BD) in the United States (104), while across the world, it is estimated that 60 million individuals suffer from BD (71).

Task-based fMRI/EEG studies that have explored connectivity patterns in $\mathrm{BD}$ population have found synchronization alterations 
that differentiate them from healthy individuals (105-107). However, in this section, we will explore the research that has studied $\mathrm{BD}$ patients during a resting-state condition.

\section{fMRI Resting-State Connectivity Findings in BD}

Multiple fMRI studies have attempted to untangle the connectivity anomalies observed in these patients, with somewhat contradicting results. Indeed, depending on the analytical method used to extract connectivity, whether it be independent component analysis (ICA) or seed-based/ROIs, wavering conclusions have been made on BD patients' corticolimbic connectivity patterns [e.g., Ref. (108)].

Although DMN activity has been closely linked to mind wandering and interoceptive thoughts $(7,40)$, it has also been shown to be germane to social cognition, which is known to be impaired in psychiatric disorders (109-111). A number of fMRI studies have summarized that most bipolar patients and their unaffected relatives have decreased connectivity within the nodes of the DMN $(36,37,112)$, between the mPFC and the insula compared with controls (113). Hyperconnectivity has been noted between the DMN and the CEN (114), the DMN and the temproparietal network $(36,37)$, and the DMN and the visual and the auditory networks $(36,37,115)$ compared to controls. Finally, the predominant result of this research in $\mathrm{BD}$, based on reviews of fMRI and DTI studies, shows altered connectivity between parts of the DMN (e.g., mPFC) and the limbic system [e.g., amygdala $(42,85,108,114,116-118)]$.

With respect to the ventrolateral PFC, contradicting findings have been reported, with some estimating enhanced connectivity with the amygdala $(108,118)$, while others diminished (119) compared to controls. In addition, a number of studies have investigated the influence of psychotic symptoms on network connectivity patterns during resting state. For instance, one paper observed hypoconnectivity within the PFC and between the dorsolateral PFC (CEN) and amygdala (120), which was predominantly present in BD patients who presented with a history of psychosis, and not in non-psychotic BD or controls.

All in all, models proposed by many researchers suggest that disruption between these keys areas, particularly connectivity involving the amygdala, underlie the occurrence of manic symptoms and inefficient emotional management $(108,118)$.

\section{EEG Resting-State Findings in BD EEG Power Modulations (Local Synchronization)}

Electroencephalography analyses of local synchronization have predominately reported group differences in the frontal region and the cingulate cortex. Examinations in modulations of local oscillatory behavior in the frontal cortex show enhanced power in alpha $(8-13 \mathrm{~Hz})(121)$, beta, and gamma $(122,123)$ frequency bands compared to controls. In the cingulate cortex, low-frequency bands, theta and alpha, had decreased power (122, $124,125)$, while higher frequency bands, beta $(15-30 \mathrm{~Hz})$ and gamma (30-50 Hz), displayed increased power compared with controls $(122,123)$.

\section{EEG Connectivity (Long-Range Synchronization)}

With respect to long-range connectivity, an EEG investigation noted decreased connectivity in the alpha $(8-12 \mathrm{~Hz})$ frequency band within frontocentral and centroparietal neural network connections of patients compared with healthy controls (124). However, more studies are needed to confirm this finding and increase the specificity of the affected regions. The accumulated evidence from multiscale modalities (e.g., fMRI and EEG) indicates that individuals affected by BD display atypical local and long-range connectivity patterns within the nodes of the DMN and between the PFC and the amygdala.

Taken together, the FMRI and EEG findings in MDD and BD patients indicate that these populations may have difficulties processing and transferring information economically that can be detectable as connectivity anomalies between and within resting-state networks. Research into pathological alterations of resting-state activity provides critical insights into large-scale network dynamics, which complement key findings that continue to emerge from task-based studies (126). In the next section, we will overview the results of MEG studies that examined restingstate connectivity and alterations in frequency band modulations within the MDD and BD. We will also examine the overlap in connectivity findings that has been reported across different resting-state neuroimaging modalities.

\section{RESTING-STATE MEG CONNECTIVITY AND MOOD DISORDERS: WHAT DO WE KNOW?}

Although still in its early days, MEG has led to important clinical insights in numerous brain disorders and has become a promising tool for clinical and translational research in psychiatry $(14,127)$. In the following, we will focus specifically on MEG contributions to elucidate resting-state alterations in mood disorders.

\section{Major Depressive Disorder}

A hierarchical approach was taken to isolate the keywords that were most appropriate for this review. First, we began with "MEG + condition," where condition was the general term for either MDD (i.e., depression) or BD (i.e., bipolar). We then refined this search by adding the term "resting" to capture studies that included a resting-state paradigm. Finally, we used the term "connectivity" to capture publications that also evaluated longrange synchronization, as resting state alone, could potentially refer to power analyses. Various combinations of these terms, as well as cross-referencing, were employed to ensure that all studies investigating MEG resting-state local power and long-range synchrony in MDD and BD patients were considered.

Here, a PubMed search using the key words "MEG + connectivity + depression" resulted in 16 hits, 12 of which were, however, unrelated to our topic of interest. Another search of the keywords "MEG + depression + resting" yielded 12 studies, with only 2 studies being relevant additions to this review. Among the articles that were found, the final count of scientific articles included in this article is 5 .

\section{Altered Resting-State MEG Power Patterns in MDD} The recent article by Jiang et al. (128) compared the oscillatory activity of MDD patients with those of age- and 
education-matched control subjects. Depression correlated with power decrease in theta $(4-8 \mathrm{~Hz})$ and alpha $(8-14 \mathrm{~Hz})$ frequency bands in the frontal and parietal areas, respectively, as well as with enhanced power in beta frequency band $(14-30 \mathrm{~Hz})$ oscillations in the DMN. Similar to EEG findings [see EEG Power Modulations (Local Synchronization)], no significant difference was found between the two populations across higher frequency bands [ $>30 \mathrm{~Hz}(128)]$.

Moreover, Li et al. (129) examined MEG signals in treatmentresistant MDD individuals who received 10 daily repetitive transcranial magnetic stimulation (rTMS) in the region of the dorsolateral PFC for two consecutive weeks. The authors normalized the spectral amplitude of five frequency bands (delta, 2-4 Hz; theta, 4-8 Hz; alpha, 8-13 Hz; beta, 13-30 Hz; and gamma, $30-50 \mathrm{~Hz}$ ) by the mean power across all bands to obtain a relative amplitude index for each oscillatory band. Moreover, they measured frontal alpha asymmetry (FAA) in all their subjects, as FAA had been previously associated with symptom severity in depression (130). This article, however, found no significant difference between patient and control subjects in terms of FAA, similar to the inconclusive results of previous electrophysiological studies on FAA, e.g., Ref. $(15,131)$.

\section{Altered Resting-State MEG Connectivity Patterns in MDD}

Table 1 summarizes the details of the four studies on MEG resting-state connectivity in MDD patients. The article by Nugent et al. (132) demonstrated that resting-state networks are altered in MDD patients compared with controls in beta frequency band
(14-30 Hz). Specifically, based on temporal ICAs and correlations in source space, they found patients to have altered connectivity between nodes of the DMN and the limbic system. Of note, long-range connectivity between the subgenual ACC and the hippocampus was diminished in patients (132). Moreover, the authors observed MDD patients to show enhanced connectivity between the right insular-temporal region and parts of the limbic system (i.e., amygdala, thalamus), and the left insular-temporal region and the angular gyrus in the parietal lobe and the precentral gyrus, which is part of the posterior region of the frontal lobe (132).

In a follow-up MEG study (133), the same authors sought out to examine the effect of ketamine on long-range synchronizations in MDD patients. The source-space connectivity patterns that were uncovered were similar to the disrupted areas found in their earlier article (132). In the beta frequency band (14-30 Hz), $0.5 \mathrm{mg} / \mathrm{kg}$ ketamine restored the abnormal hyperconnection between amygdala and insula-temporal regions to normal levels. Interestingly, the authors noted that ketamine appeared to decrease all connectivity patterns across all the regions of the brain, regardless of the subjects' baseline activity.

Pathak et al. (134) recently used the magnitude-squared coherence to estimate long-range connectivity in depressed individuals before and after rTMS in the dorsolateral PFC at $10 \mathrm{~Hz}$. Their source-space findings (via minimum-norm estimate) reveal that symptom improvement after 4 weeks of treatment correlated with changes in the connectivity within the DMN. Post-TMS, MDD patients found increased coherence between the dorsolateral PFC and the amygdala and the

TABLE 1 | MEG resting-state connectivity studies in major depressive disorder.

\begin{tabular}{|c|c|c|c|c|c|}
\hline Reference & Frequency range & Methods & Patients & Controls & Main findings \\
\hline (129) & $\begin{array}{l}\text { Delta: } 2-4 \mathrm{~Hz} \\
\text { Theta: } 4-8 \mathrm{~Hz} \\
\text { Alpha } 8-13 \mathrm{~Hz} \\
\text { Beta: } 13-30 \mathrm{~Hz} \\
\text { Gamma: } 30-50 \mathrm{~Hz}\end{array}$ & $\begin{array}{l}\text { Frontal alpha asymmetry } \\
\text { and voxel-based partial } \\
\text { correlation to examine } \\
\text { connectivity in prefrontal- } \\
\text { thalamic circuit (based } \\
\text { on PET) } \\
\text { Sensor-space analysis } \\
3 \text { min eyes open }\end{array}$ & $\begin{array}{l}30 \text { MDD received } \\
\text { rTMS, } 6 \text { males } \\
17 \text { responders: mean } \\
\text { age: } 51.9 \pm 10.5 \\
13 \text { non-responders: } \\
\text { mean age: } 50.1 \pm 6.2\end{array}$ & $\begin{array}{l}50 \text { controls } \\
14 \text { males } \\
\text { mean age: } \\
49.1 \pm 7.0\end{array}$ & $\begin{array}{l}\text { MDD appeared to have impaired prefronto-thalamic functional } \\
\text { connections compared to controls. rTMS resolved this pattern in } \\
\text { those who responded to treatment after } 2 \text { weeks of treatment at } \\
10 \mathrm{~Hz} \text { in their dorsolateral PFC }\end{array}$ \\
\hline (132) & $14-30 \mathrm{~Hz}$ & $\begin{array}{l}\text { Correlation } \\
\text { Source-space analysis } \\
4.17 \text { min eyes closed }\end{array}$ & $\begin{array}{l}33 \text { MDD } \\
22 \text { males } \\
\text { Mean age: } 42.8 \pm 9.9\end{array}$ & $\begin{array}{l}19 \text { controls } \\
11 \text { males } \\
\text { Mean age: } \\
39.3 \pm 6.5\end{array}$ & $\begin{array}{l}\text { Patients had reduced correlations between the subgenual } \\
\text { ACC and hippocampus in a network with primary nodes in the } \\
\text { precentral and middle frontal gyri. Patients showed increased } \\
\text { correlations between insulotemporal nodes and amygdala } \\
\text { compared to controls }\end{array}$ \\
\hline (133) & $14-30 \mathrm{~Hz}$ & $\begin{array}{l}\text { Correlation } \\
\text { Source space } \\
4.17 \text { min eyes closed }\end{array}$ & $\begin{array}{l}13 \mathrm{MDD} \\
11 \text { males } \\
\text { Mean age: } \\
45.0 \pm 13.2\end{array}$ & $\begin{array}{l}18 \text { controls } \\
12 \text { males } \\
\text { Mean age: } \\
39.0 \pm 7.3\end{array}$ & $\begin{array}{l}\text { Patients displayed enhanced connectivity between insulotemporal } \\
\text { areas and amygdala that were reduced to normal levels after } \\
\text { ketamine treatment }\end{array}$ \\
\hline (134) & $\begin{array}{l}\text { Delta: } 2-4 \mathrm{~Hz} \\
\text { Theta: } 5-7 \mathrm{~Hz} \\
\text { Alpha: } 8-12 \mathrm{~Hz} \\
\text { Beta: } 15-29 \mathrm{~Hz} \\
\text { Gamma: } 30-59 \mathrm{~Hz}\end{array}$ & $\begin{array}{l}\text { Magnitude-squared } \\
\text { coherence. Seed: } \\
\text { dorsolateral PFC } \\
\text { Source space } \\
6 \text { min eyes closed }\end{array}$ & $\begin{array}{l}5 \text { MDD received } \\
\text { TMS, } 1 \\
\text { non-responder }\end{array}$ & $\mathrm{n} / \mathrm{a}$ & $\begin{array}{l}\text { Symptom improvement by } 10 \mathrm{~Hz} \text { rTMS increased connectivity } \\
\text { between dorsolateral PFC and amygdala, and dorsolateral PFC } \\
\text { and pregenual ACC in delta band. rTMS decreased connectivity } \\
\text { between dorsolateral PFC and subgenual ACC }\end{array}$ \\
\hline
\end{tabular}


pregenual cingulate cortex in the delta frequency band, as well as decreased coherence in the gamma band between the dorsolateral PFC and the subgenual ACC before treatment (134). The findings of this article could imply that baseline connectivity patterns in MDD involve diminished coherence between dorsolateral PFC-amygdala and dorsolateral PFC-pregenual cingulate cortex, along with enhanced coherence between dorsolateral PFC-subgenual ACC. Moreover, the outcome of this study underlines the importance of analyzing and reporting the type of treatment received by patients as it directly affects the neural network organization.

Finally, Li and colleagues' (129) longitudinal study explored connectivity in alpha frequency band oscillations in the PFC (via MEG) and glucose metabolism in the thalamus (via PET), which is typically underactive in MDD patients. For the analysis of PFC and thalamus connectivity, patients were divided into binary categories of responders and non-responders to 2-week treatment of rTMS at $10 \mathrm{~Hz}$. Patients were categorized based on their symptom ratings on the Hamilton Depression Rating Scale in the eighth week of the study. This type of antidepressant treatment was able to rescue the disrupted functional connection in responders 14 weeks after the start of the study, while this did not succeed in non-responders. Thus, according to the authors, their sensor-space finding could be seen as additional evidence that the strength of prefrontothalamic connectivity could be an index of depressive symptoms, as previously observed in fMRI studies (79).

The main finding of these MEG papers speak of altered longrange connectivity between the DMN and the CEN. In particular, the resting-state MEG literature supports previous fMRI studies that have demonstrated the implication of the subgenual cingulate cortex, the dorsolateral PFC, and the thalamus in illness severity and symptomatology in MDD [e.g., Ref. (79)]. Importantly, the subgenual cingulate cortex is typically targeted for DBS and rTMS in treatment-resistant depressed individuals and is thus critical to the understanding of their resting-state neural networks (97, $98,135,136)$.

\section{Relationship to Task-Based MEG Findings}

This section explores task-based MEG studies that corroborate connectivity results from resting-state MEG studies in MDD.

A number of studies have investigated the long-range connectivity patterns that emerge during affective and cognitive tasks in psychiatric patients. Among their findings, the diminished long-range synchronization between the dorsolateral PFC and the amygdala, observed recently in resting-state MEG by Pathak et al. (134), was also observed by Lu et al. (137). Indeed, the authors explored effective connectivity within the prefrontallimbic system circuit using dynamic causal modeling analysis (137). During the affective task, subjects viewed 3-s clip of faces who were eating, neutral, happy, or sad and then indicated by button-press if the expression was sad or not. Under the most optimal model, patients had decreased connectivity from the dorsolateral PFC to the amygdala compared with controls. The authors hypothesized that this could explain part of the dysfunction observed in MDD patients with respect to the integration of both affective and cognitive information for overt behavior.
Other connectivity alteration in MDD patients have also been noted in task-based MEG studies. Specifically, a measure of wavelet coherence has shown enhanced connectivity between the ACC and the amygdala in the gamma (30-48 Hz) and in the delta (below $4 \mathrm{~Hz}$ ) frequency bands (138). Moreover, enhanced connectivity between the amygdala and the inferior frontal gyrus, as well as between the amygdala and the ACC, in patients, was found to be highly discriminative features during the aforementioned affective task to differentiate MDD and control subjects (139). These connectivity alterations have yet to be observed in resting-state MEG findings. It may be the case that these differences in long-range synchronizations are due to the nature of the task or, rather, that they are best detected by these emotion-based paradigms.

Finally, Salvadore et al. (140) used the widespread workingmemory task, N-back, to investigate how the connectivity patterns of MDD patients change before and after a single ketamine infusion. During this task, subjects were asked to keep in mind a stimulus (number between 1 and 4) and to respond when it was matched to the observed stimulus either right away or one or two trials previously. By using source-coherence analysis, the authors observed that the connectivity strength between the pregenual ACC and the left amygdala correlated negatively with the effect of treatment. Indeed, stronger coherence between these two regions prior to ketamine infusion correlated with improvement in symptoms. Similar findings about altered long-range synchronization between the subgenual ACC and the amygdala have been observed in intracranial EEG/DBS studies $(97,98)$. Given the reoccurring report of involvement of these brain regions, future resting-state MEG studies could clarify whether this pattern of connectivity alteration pertains to the nature of the task or to the intrinsic neural organization in MDD.

\section{Strengths and Limitations of Resting-State MEG Studies in MDD Population}

An important limitation that connectivity studies might display is that of being conducted at sensor level rather than source level. Although most of the reported MDD studies were conducted in source space, the article by $\mathrm{Li}$ et al. (129) was in sensor space, where only 26 gradiometers (out of a possible 306 channels) from the frontal region were used. However, the article had a major strength of employing a multimodal approach to studying connectivity (MEG, PET, and TMS), which included an anatomical T1 from MRI to obtain anatomical precisions. This allowed access to a richer set of information than what is provided using a single neuroimaging tool.

Next, exploring specific frequency bands can also be a limitation. Indeed, in the article by Nugent et al. (132), only the beta band frequency range was explored, while Li et al. (129) reported only on alpha frequency band oscillatory behavior. A strength of Nugent et al. (132) is that the authors took additional quality control steps (to verify the reliability of their ICA estimates), they tested the reliability of their results by comparing it with a second data set (unmatched groups) and, importantly, they included unmedicated MDD subjects. By doing so, the authors allowed to examine intrinsic connectivity prior to pharmaceutical effects. 
Furthermore, the metric of coherence and correlations can raise questions about the spatial accuracy of the long-range synchronizations observed due to potential field spread effect (see Challenges, Pitfalls, and Methodological Recommendations for Future Studies for further details).

Finally, small sample size can be problematic in the interpretation of findings. In their recent study, Nugent et al. (133) explored the effect of ketamine on long-range synchronization and on symptoms scores as assessed by the Mania and Depression Rating Scale in a subset of patients from their previous study (132). However, this was performed in a small number of subjects. Non-parametric statistical tests were applied to compensate for their cohort of patients. Similarly, while Pathak et al.s (134) study was important to evaluate the longitudinal effect of repetitive TMS on neural network connectivity, the small sample of patients $(n=5)$ and lack of multiple comparisons put the findings of this paper at risks of type I error, a fact acknowledged by the authors. While it is important to evaluate promising treatments, it would be interesting to evaluate its effect on connectivity patterns in a larger cohort of patients to increase reliability.

\section{Bipolar Disorder}

A PubMed search of the key words "MEG + connectivity + bipolar" resulted in no findings. However, a search of the key words "MEG + bipolar + resting" yielded three studies, one of which was an EEG study (already discussed in fMRI Resting-State Connectivity Findings in MDD).

\section{Altered Resting-State MEG Power Patterns in BD}

Al-Timemy et al. (141) were able to successfully classify BD and control populations using MEG resting-state spectral features within the delta $(1.5-4 \mathrm{~Hz})$, theta $(4-8 \mathrm{~Hz})$, alpha $(8-13 \mathrm{~Hz})$, beta $(13-30 \mathrm{~Hz})$, and gamma $(30-40 \mathrm{~Hz})$ frequency bands. Relative power modulations in delta and theta frequency bands in the posterior region of the brain were observed to be significantly different between patients and healthy controls (141). However, the direction in these differences was not specified. The authors of this study also explored median frequency (MF), described as the frequency that divides the area under the curve of the power map (1.4-40 Hz) into two. Their analysis found MF of BD patients to range between 9.92 and $12.54 \mathrm{~Hz}$ depending on the examined brain region. Furthermore, unlike healthy control subjects who demonstrated a positive correlation between their $\mathrm{MF}$ and age, BD patients had a negative correlation between MF and age (141).

\section{Altered Resting-State MEG Connectivity Patterns in BD}

Table 2 summarizes the details of the relevant study that have been published on BD. Chen et al. (142) had an interesting, although small, pool of euthymic (no overt depressive or manic symptoms) BD-I patients that was compared with matched healthy controls. The authors focused on the frontal cortex activity, and thus, oscillatory modulations in only 11 of their 306 MEG channels were reported. Their spectral analysis across pairs of channels was performed using a derivative of the similarity index (SI) framework used by Arnhold and colleagues (143). Differences between patients and controls were noted based on global SI of channel pairs: patients displayed an increase in the synchronization of delta band $(2-4 \mathrm{~Hz})$ frequencies and a decrease in beta band (12-24 Hz) frequencies within nodes of the frontal cortex (142). While there is a number of MEG studies that have examined alterations of spectral power in BD during tasks [e.g., Ref. (144, 145)], as it stands, and to our knowledge, the article by Chen et al. (142) is so far the only resting-state MEG study that has evaluated the functional connectivity in BD population.

\section{Relationship to MEG Task-Based Studies}

To the best of our knowledge, no MEG task-based study has explored long-range synchronizations in BD. However, EEG resting-state studies, such as one by Kim et al. (124), have observed disrupted connections within the PFC of BD patients compared with controls. Future MEG studies, with and without tasks, could help elucidate more specific neural network patterns that are either specific to the neural organization of BD patients, or, alternatively, to altered patterns of information processing.

\section{Strengths and Limitations of Resting-State MEG Studies in BD Population}

Although of important value, the resting-state MEG study by Chen et al. (142) exploring long-range synchronization had a number of limitations. For instance, although significant information can be gathered by exploring euthymic patients (i.e., with no overt depressive or manic symptoms), the pool of subjects was relatively small $(n=10)$. Moreover, in addition to being conducted in sensor space, the authors focused on the frontal cortex activity, with oscillatory modulations of only 11 of their $306 \mathrm{MEG}$ channels being reported. The investigation of the neural network connectivity pattern of BD using MEG is clearly still in its early days, and more studies are needed to elucidate the key connectivity patterns that define this illness.

TABLE 2 | MEG resting-state connectivity studies in BD.

\begin{tabular}{|c|c|c|c|c|c|}
\hline Reference & Frequency range & Methods & Patients & Controls & Main findings \\
\hline (142) & $\begin{array}{l}\text { Delta: } 2-4 \mathrm{~Hz} \\
\text { Theta: } 4-8 \mathrm{~Hz} \\
\text { Alpha:8-12 Hz } \\
\text { Beta: } 12-24 \mathrm{~Hz}\end{array}$ & $\begin{array}{l}\text { Similarity index; using } 11 \\
\text { sensors from the frontal lobe } \\
\text { Sensor space } \\
2 \text { min eyes closed }\end{array}$ & $\begin{array}{l}10 \text { euthymic BD-I } \\
5 \text { males } \\
\text { Mean age: } \\
32.5 \pm 10.3\end{array}$ & $\begin{array}{l}10 \text { controls: } 5 \text { males } \\
\text { Mean age: } \\
32.2 \pm 11.6\end{array}$ & $\begin{array}{l}\text { Increased synchronization of } \delta \text { frequency oscillations } \\
\text { and decreased synchronization of } \beta \text { frequency } \\
\text { oscillations in the frontal lobe in BD compared to } \\
\text { controls }\end{array}$ \\
\hline
\end{tabular}

Overview of MEG resting-state studies examining changes in long-range connectivity patterns in subjects with BD.

$B D$, bipolar disorder; BD-I, bipolar disorder type I; MEG, magnetoencephalography. 


\section{Summary of MEG Findings}

The present overview shows that MDD individuals have enhanced connectivity patterns within nodes of the DMN (as evidenced by resting-state fMRI and EEG studies), as well as altered connectivity between areas of the DMN and the limbic system (particularly between subgenual ACC and hippocampus, as evidenced by $\mathrm{fMRI}$ and MEG). Moreover, there is evidence for hypoactivity between regions of the CEN and the limbic system (particularly dorsolateral PFC and amygdala, as observed through fMRI and MEG), alterations between the nodes of the DMN and the CEN (particularly hyperconnectivity between the subgenual ACC and the dorsolateral PFC, as noted using fMRI, EEG, and MEG) and, finally, hyperconnectivity between the insula and the limbic system (amygdala, as noted by fMRI and MEG studies). Overall, projections from and to the subgenual ACC, as well as the dorsolateral PFC, appear to be critical in the treatment and expression of depressive symptoms. Figure 1 illustrates the key patterns of altered long-range connectivity in MDD patients, observed using both MEG and fMRI (and in some cases also with EEG).

Most of the work in BD arises from resting-state fMRI research, which has observed altered connectivity between areas of the DMN and the limbic system (notably between the mPFC and the amygdala), hyperconnectivity between nodes of the DMN and CEN (particularly between the medial PFC and dorsal/ventrolateral PFC), and hyperconnectivity between the ventrolateral PFC and the amygdala. Across all three neuroimaging modalities of fMRI, EEG, and MEG, altered (mainly decreased) connectivity in the PFC has been noted. This hypoactivity in the frontal lobe has been thought to be due to the presence of psychotic symptoms in a proportion of BD patients (120). Hence, overall, the amygdala appears to be a key region in BD. Given the scarcity of resting-state connectivity studies in the $\mathrm{BD}$ population, we could not illustrate by a figure the intrinsic patterns affected in this pathology. This exemplifies the important need of conducting more resting-state MEG studies to support (and further characterize) the functional findings that are observed through an MRI in BD. Such electrophysiologicalbased results, especially if conducted in source space, could immensely improve our understanding of the fundamental network disorganization of this pathology.

\section{CHALLENGES, PITFALLS, AND METHODOLOGICAL RECOMMENDATIONS FOR FUTURE STUDIES}

The assessment of resting-state connectivity patterns in psychiatric populations with MEG is a fairly new field still faced with substantial technical challenges. This section addresses the most important methodological issues that need to be understood and taken into account. Most importantly, in addition to delineating current limitations, we provide suggestions and methodological recommendations to help the field move forward.

\section{Choosing an Appropriate Connectivity Metric: Lack of a Gold Standard}

In contrast to functional connectivity estimations in fMRI, where the primary measure is straightforward correlation between the BOLD time series in various voxels or ROIs, MEG connectivity estimation is a more complex endeavor (146). This complexity has two distinct causes: first, many common connectivity metrics come with important methodological pitfalls, and second, the richness and multifaceted nature of neuromagnetic signals can allow the exploration of a wide variety of interactions (e.g., phase-amplitude coupling, phase-phase coupling). A question that is thus reoccurring is the following: Which coupling method

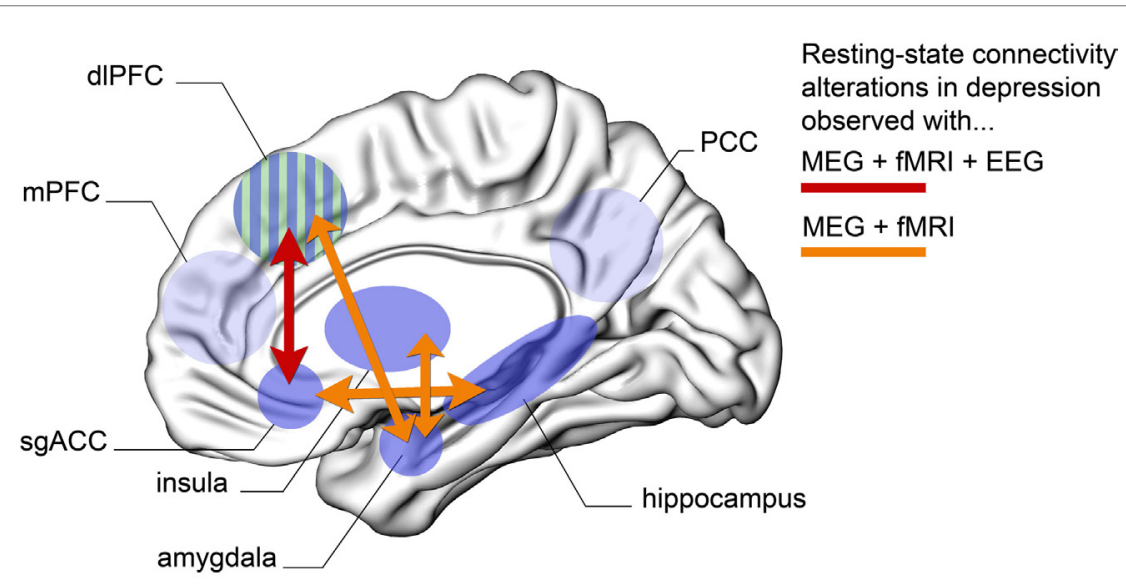

FIGURE 1 | Schematic overview of the key brain regions that show abnormal long-range connectivity patterns in subjects with MDD. Here, we only show areas for which evidence has been confirmed across at least MEG and fMRI modalities. Orange arrows represent altered connection between two brain regions that has been confirmed using both MEG and fMRI resting-state paradigms. Red arrow represents altered resting-state connectivity between two regions that has been confirmed across MEG, EEG, and fMRI. Abbreviations: MEG, magnetoencephalography; EEG, electroencephalography; fMRI, functional magnetic resonance imaging; dIPFC, dorsolateral prefrontal cortex; mPFC, medial prefrontal cortex; sgACC, subgenual anterior cingulate cortex; PCC, posterior cingulate cortex; MDD, major depressive disorder. (Green-blue striped area represents dIPFC shown here from a medial view perspective for convenience.) 
should one use? Choosing the right connectivity metric to assess long-range MEG coupling is a critical decision that can easily bias the results of the study.

Generally speaking, most of the commonly used interaction measures (e.g., coherence or phase-locking value) face limitations caused by linear mixing. This is a problem often referred to as field spread (MEG) or volume conduction (EEG) when dealing with sensor level data, or signal leakage when exploring sourcelevel data (48). Although several coupling measures have been proposed [e.g., Ref. $(47,51,147-149)$ ], there is no consensus as to which one provides the best estimate of true cortical interaction. Ideally a reliable and robust measure would fulfill two criteria: it would be (a) minimally sensitive to linear mixing and (b) maximally sensitive to the specific physiological mechanisms that underlie the neural interaction. Indeed, there is not much use for a technique that is entirely immune to field spread effects if the quantity that it estimates does not capture the true physiological functional interaction. Without a clear hypothesis about the precise long-range physiological coupling mechanism, one compromise that may well be worth considering is to examine connectivity through a combination of complementary metrics. This could be achieved, for instance, through joint exploration of phase-based and amplitude-based measures. In this context, we encourage the assessment of phase-lag index $(52,66)$ in parallel to band-limited envelope correlations (149-151).

\section{Sensor- vs Source-Level Analyses}

Although important information can be gained from combining sensor-level MEG data with advanced connectivity metrics, source-space network assessments are key to simultaneously identify the neuroanatomical substrates and functional role of the involved networks. Moreover, source-level estimation is critical to help bridge the gap between MEG and fMRI findings in the field of psychiatry. Although most of the studies reviewed here use source-space connectivity measurements (16, 132-134, 152, 153), most electrophysiological studies still conduct their analyses in sensor space. A question one might ask is which source estimation technique would be considered most efficient for the specific aim of measuring resting-state MEG source-level connectivity patterns. Most of the available techniques differ in their underlying assumptions about the properties of the sources (18, 154). Attempts to infer the most appropriate source reconstruction method based on the real data are hard to evaluate given that the ground truth is unknown. Using simulations can help us appreciate the strengths and limitations of a coupling method, but the extent to which it is useful for its application to real data is difficult to assess. The lack of a reliable gold standard is a concern for MEG analyses in general and for MEG resting-state network assessments in particular. One could argue that the discussion on identifying the best inverse method might be considered an ill-posed question in itself with no unique solution. Nevertheless, we expect most families of source estimation methods (e.g., minimum-norm or spatial filters) to provide similar results when applied properly. Above all, what is most important is to understand the pitfalls and limitations of a chosen method and their impact on source-space connectivity estimations (155).

\section{Stability of MEG-Based Resting-State Networks Estimations}

A challenge that is not yet entirely resolved is that of the robustness and consistency of MEG-based resting-state estimation over time and across participants. Recent research has addressed the reliability of MEG resting-state connectivity metrics (156) and its test-retest reliability (157). Both intersubject and intrasubject consistency of MEG resting-state network estimations have been investigated, and it has been found that, while variability exists, seed-based and appropriate averaging techniques allow to compare subjects between and within groups (158). Epoch length is a potential source of variability that also needs to be considered when measuring resting-state connectivity [for an EEG study, see Ref. (159)]. Such parameters need to be carefully chosen prior to designing the resting-state MEG acquisition protocol. In addition, when it comes to clinical patients, it is recommended to acquire longer resting-state data than for healthy subjects as there is a higher risk of artifacts [see Contrasting Controls and Patients: Differences in Artifacts and Signal-to-Noise Ratio (SNR)]. The psychiatry-focused studies that were reviewed here used recording lengths that varied between 2 and $6 \mathrm{~min}$, although most of them used 3-4 min. A gold standard for data length in MEG resting-state protocols is lacking. Three minutes seems to be an acceptable lower limit and 4-5 min can be considered a reasonable recommendation and likely necessary in the case of patient populations (where subsequent data loss is expected because of more artifacts). Similarly, there is currently no consensus on whether resting-state protocols should be performed with eyes open or closed. About half of the MEG resting-state studies reviewed here were carried out with eyes open and the other half with eyes closed. Because of the relatively low number of restingstate studies in MEG and because of different methodological constraints in MEG and fMRI, it seems too early to make a final decision. Given this, we would recommend acquiring both eyes open and eyes closed if possible. If this is not feasible, we suggest using eyes open with a fixation cross to minimize eye movements. Eyes closed resting state is associated with strong alpha power increases (which might in theory interfere with subsequent network analyses), and participants are at a higher risk of getting drowsy and potentially falling asleep during the recording.

\section{Contrasting Controls and Patients: Differences in Artifacts and Signal-to- Noise Ratio (SNR)}

Comparisons between MEG resting-state connectivity patterns obtained in controls and patients are faced with additional difficulties caused by the pathological conditions. Increased head and body movement artifacts, eye blinks, and saccades in patient populations are not uncommon, and they all lead to poorer data quality compared with data acquired in healthy subjects. For equal MEG scanning durations, artifact rejection techniques will ultimately lead to less data being preserved for the patients, which may in turn yield lower SNR in patient data compared with controls. These differences in SNR must be avoided, or at least controlled for, since they will lead to differences in functional 
interaction patterns that may have nothing, or little, to do with the pathology at hand and rather reflecting differences in data quality. Minimizing data rejection through the use of artifact correction techniques such as ICAs could be of interest, although the differential application of ICA to the two groups (i.e., more extensive in the case of patient data) could also lead to differences that may bias connectivity findings and data interpretation. To address artifact-related SNR discrepancies between patients and controls, we recommend planning to acquire more data in patients from the start of the project or alternatively to use a subsample of data from the controls to achieve comparable SNR across the two groups.

A second, often overlooked, issue is that pathological changes in local signal amplitude can affect the estimation of long-range connectivity in patients and thereby lead to group differences that are in fact a reflection of inadequate or unreliable coupling estimation. This can occur because lower signal amplitudes (that equate noise levels) will de facto lead to lower SNR. A lower SNR within a given frequency band can affect, for instance, the estimation of phase. In such a case, the reduction or vanishing of a measure of interareal phase coupling, compared to controls, cannot be taken as an indication of connectivity break down, rather it is the result of poor phase estimation in patients due to lower local SNR. This phenomenon will also affect interareal cross-frequency phaseamplitude coupling. Overcoming such limitations is not trivial. A good rule of conduct is not to focus on interareal interaction measures alone, but to systematically calculate spectral power in the frequencies and nodes of interest. If the powers show statistically significant differences across the groups, one could attempt to randomly use subsamples of data to control for the effect of amplitude across the two groups (bootstrapping and stratification techniques could be useful here).

\section{Effect of Age and Medication on Connectivity Patterns in Psychiatry}

In both healthy and pathological populations, age has been shown to be an important variable that can affect brain structure, cognitive functions, and connectivity patterns (160-162). At the anatomical level, volumes of cortical gray and white matter change with age. On the one hand, among neurotypically developed individuals, gray matter density of frontal and parietal lobes displays an inverted U pattern, with volume increasing until adolescence, then declining. However, this may not be the case of other brain regions $(162,163)$. On the other hand, white matter volume appears to steadily increase until around 30 years of age $(162,163)$. At the functional level, task-based studies in fMRI have observed focal increases in activity with age, for instance, in the dorsolateral PFC, ventrolateral PFC, and premotor cortex (164). Changes in connectivity between certain brain regions also seem to take place with age. Of note, long-range synchronizations that underline the processes of cognitive functioning (e.g., attention, working-memory, inhibition) appear to grow in strength until the third decade of life $(161,165)$. Compared to these findings in healthy cohorts, deficits observed in illnesses, such as schizophrenia, are found to be similar, albeit with steeper decline in some function, such as abstract thought [e.g., Ref. (160)].
Age of illness onset is also an important factor to take into consideration as early/preadolescence onset of psychopathologies typically correlate with worse prognosis and more severe clinical symptoms $(166,167)$. Moreover, in BD, early onset is seen to be linked to more comorbid disorders (e.g., anxiety, substance abuse), shorter euthymic periods, and more attempts of suicide $(168,169)$. Taken together, age is a critical factor when conducting connectivity analyses or correlations between symptoms and connectivity patterns, particularly in psychiatric population, to ensure that statements made about group differences are in fact due to true discrepancies between the evaluated cohorts and not due to an age effect (170).

Medication is also a variable for that has substantial effects on the neural network of psychiatric patients, with different types of pharmacotherapies impacting connectivity in distinct ways (e.g., selective seratonergic vs noradregenic reuptake inhibitor) (171). A review of longitudinal MRI-based studies noted that part of the gray matter volume decreases and ventricle enlargement in schizophrenia patients could be explained by cumulative exposure to antipsychotic treatment (172). In MDD, antidepressant treatment seems to modify the connectivity between the nodes of the DMN, as well as corticolimbic connectivity, at both rest and during affective tasks [e.g., Ref. $(173,174)]$. However, other studies find the effect of psychotropics on functional connectivity to be inconclusive (175). Part of the difficulty in untangling the influence of treatment lies in the complexity of conducting longitudinal studies, which ideally include drug naïve patients who are either individuals at risk of developing a psychiatry illness or first-episode psychosis or mania patients, as well as chronic patients to compare with. A number of studies that have investigated birth cohorts [e.g., Ref. (176)] have enlightened the field the most as they take into account maximal information regarding context, neurodevelopmental factors, environmental influences, longitudinal notes on symptoms, and treatments effects.

Finally, it is important to note that non-medication drugs, such as nicotine and caffeine, also appear to alter resting-state networks in healthy and clinical populations. Evidence of this effect has been reported using fMRI (177-182) and MEG (183). Future connectivity studies should incorporate these variables in their analyses.

\section{CONCLUSION AND FUTURE DIRECTIONS}

This review is the first of its kind to examine the literature's findings on resting neural network connectivity patterns of BD and major depression disorder, based on MEG studies. A global analysis of current scientific papers demonstrate that the two illnesses display functional abnormalities that affect the way information is integrated, locally, and transferred from one brain region to another through long-range connections. Moreover, this review illustrated that resting-state neuroimaging paradigms are a useful way to access the disorganized brains of individuals with psychopathologies. Finally, although still in its early days, MEG carries the potential to significantly advance our understanding of large-scale network alterations associated with psychiatric disorders (184). 
Overall, the PFC, in particular the mPFC which is at the core of the DMN and of social cognition, is affected across both psychopathologies. Given that this brain region is one of the last to develop during neurodevelopment $(185,186)$, it is not surprising that most mental health issues arise during adolescence and that any early brain damage, detrimental environmental factor, or oxidative stress can affect a person's personality, theory of mind, emotional maturity, empathy, and healthy resting neural wiring (187-189). Of note, among depressed individuals, patterns of dysfunctional connectivity are repeatedly observed across the three major neuroimaging modalities reviewed (fMRI, EEG, and MEG), particularly altered long-range connectivity between the DMN and the limbic system, as well as between the DMN and the CEN. In MDD population, the recurrent dysfunctional connectivity patterns involved the subgenual ACC. As for the BD literature, the most consistent findings stemmed from resting fMRI studies, where functional connectivity was altered between regions of the DMN and the amygdala in BD.

An explanation for the imbalance in the amount of scientific papers published in these two mood disorders could be that depression is the mental illness affecting the largest percentage of individual worldwide in its various forms (e.g., MDD, postpartum depression, seasonal onset depression), while $\mathrm{BD}$ is symptomatically more complex and heterogeneous. Thus, when interpreting neuroimaging results, researchers should consider the effect of additional psychological factors, such as manic/cyclic mood and history of psychosis (120), as well as medication when attempting to untangle the connectivity pattern affiliated with $\mathrm{BD}$.

Resting-state MEG is expected to continue gaining momentum in psychiatry. One promising application is its ability to enhance the understanding of how neuromodulation (e.g., rTMS) can change the neural circuitry of mood disorder patients. Indeed, there is cumulating evidence that rTMS might reduce symptoms in MDD patients (190-193). Hence, exploring the different ways this tool changes resting-state networks after stimulation could

\section{REFERENCES}

1. Dutta A, McKie S, Deakin JF. Resting state networks in major depressive disorder. Psychiatry Res (2014) 224(3):139-51. doi:10.1016/j. pscychresns.2014.10.003

2. Hanford LC, Nazarov A, Hall GB, Sassi RB. Cortical thickness in bipolar disorder: a systematic review. Bipolar Disord (2016) 18(1):4-18. doi:10.1111/ bdi. 12362

3. Northoff G. How do resting state changes in depression translate into psychopathological symptoms? From 'spatiotemporal correspondence' to 'spatiotemporal psychopathology'. Curr Opin Psychiatry (2016) 29(1):18-24. doi:10.1097/YCO.0000000000000222

4. Broyd SJ, Demanuele C, Debener S, Helps SK, James CJ, Sonuga-Barke EJ. Default-mode brain dysfunction in mental disorders: a systematic review. Neurosci Biobehav Rev (2009) 33(3):279-96. doi:10.1016/ j.neubiorev.2008.09.002

5. Greicius MD. Resting-state functional connectivity in neuropsychiatric disorders. Curr Opin Neurol (2008) 24(4):424-30. doi:10.1097/ WCO.0b013e328306f2c5

6. Fox MD, Greicius M. Clinical applications of resting state functional connectivity. Front Syst Neurosci (2010) 4:19. doi:10.3389/fnsys.2010.00019

7. Raichle ME, MacLeod AM, Snyder AZ, Powers WJ, Gusnard DA, Shulman GL. A default mode of brain function. Proc Natl Acad Sci U S A (2001) 98(2):676-82. doi:10.1073/pnas.98.2.676 help further elucidate connectivity patterns in these patients, and possibly lead to new neuromodulation targets for the treatment of MDD.

Our recommendations for future studies are to further explore the potential of examining functional and effective neural network connectivity in psychiatric disorders using a combination of tools, multimodal imaging techniques, yet employ common terminology (194). As far as MEG is concerned, performing the connectivity analysis in source space is highly recommended to improve the interpretability of the findings. In addition, the informed choice of the connectivity framework and network metrics is critical to avoid misinterpretations. The use of advanced methods such as graph metrics or machine learning as a data mining tool in this field is also a promising venue for future research. By doing so, a more complete picture of how mental illness affects information propagation can be acquired, thus allowing for the development of more efficient treatment for patients.

\section{AUTHOR CONTRIBUTIONS}

GA and KJ designed and wrote the review; GA, A-SH, EC, VM, $\mathrm{DA}, \mathrm{TT}$, and $\mathrm{KJ}$ conducted the literature research, the critical assessment thereof, and comprehensive proofreading of the manuscript.

\section{ACKNOWLEDGMENTS}

GA was supported in part by a CERNEC scholarship. EC was supported in part by a PhD scholarship from Ecole Doctorale InterDisciplinaire Sciences-Santé, Lyon, France, and by $\mathrm{PhD}$ funding from the Natural Sciences and Engineering Research Council of Canada (NSERC). VM was supported by NSERC Undergraduate Student Research Awards. KJ acknowledges funding from the Canada Research Chairs program and NSERC Discovery Grant (RGPIN-2015-04854).

8. White T, Ehrlich S, Ho BC, Manoach DS, Caprihan A, Schulz SC, et al. Spatial characteristics of white matter abnormalities in schizophrenia. Schizophr Bull (2013) 39(5):1077-86. doi:10.1093/schbul/sbs106

9. Friston KJ. Functional and effective connectivity: a review. Brain Connect (2011) 1(1):13-36. doi:10.1089/brain.2011.0008

10. Varela F, Lachaux JP, Rodriguez E, Martinerie J. The Brainweb: phase synchronisation and large-scale integration. Nat Rev (2001) 2:229-39. doi:10.1038/35067042

11. Luo L, Rodriguez E, Jerbi K, Lachaux JP, Martinerie J, Corbetta M, et al. Ten years of nature reviews neuroscience: insights from the highly cited. Nat Rev Neurosci (2010) 11(10):718-26. doi:10.1038/nrn2912

12. Hasey GM, Kiang M. A review of recent literature employing electroencephalographic techniques to study the pathophysiology, phenomenology, and treatment response of schizophrenia. Curr Psychiatry Rep (2013) 15(9):388. doi:10.1007/s11920-013-0388-x

13. Başar E, Gölbaşı BT, Tülay E, Aydın S, Başar-Eroğlu C. Best method for analysis of brain oscillations in healthy subjects and neuropsychiatric diseases. Int J Psychophysiol (2015) 103:22-42. doi:10.1016/j.ijpsycho.2015.02.017

14. Siekmeier PJ, Stufflebeam SM. Patterns of spontaneous magnetoencephalographic activity in patients with schizophrenia. J Clin Neurophysiol (2010) 27(3):179-90. doi:10.1097/WNP.0b013e3181e0b20a

15. Jesulola E, Sharpley CF, Bitsika V, Agnew LL, Wilson P. Frontal alpha asymmetry as a pathway to behavioural withdrawal in depression: research findings and issues. Behav Brain Res (2015) 292:56-67. doi:10.1016/j.bbr.2015.05.058 
16. Robinson SE, Mandell AJ. Mutual information in a MEG complexity measure suggests regional hyper-connectivity in schizophrenic probands. Neuropsychopharmacology (2015) 40(1):251-2. doi:10.1038/npp. 2014.217

17. Cohen D. Magnetoencephalography: detection of the brain's electrical activity with a superconducting magnetometer. Science (1972) 175(4022):664-6. doi:10.1126/science.175.4022.664

18. Gross J, Baillet S, Barnes GR, Henson RN, Hillebrand A, Jensen O, et al. Good practice for conducting and reporting MEG research. Neuroimage (2013) 65(100):349-63. doi:10.1016/j.neuroimage.2012.10.001

19. Jerbi K, Lachaux JP, N'Diaye K, Pantazis D, Leahy RM, Garnero L, et al. Coherent neural representation of hand speed in humans revealed by MEG imaging. Proc Natl Acad Sci U S A (2007) 104(18):7676-81. doi:10.1073/ pnas.0609632104

20. Hamalainen M, Hari R, Ilmoniemi RJ, Knuutila J, Lounasmaa OV. Magnetoencephalography - theory, instrumentation, and applications to noninvasive studies of the working human brain. Rev Mod Phys (1993) 65(2):413-505. doi:10.1103/RevModPhys.65.413

21. Hamandi K, Routley BC, Koelewijn L, Singh KD. Non-invasive brain mapping in epilepsy: applications from magnetoencephalography. J Neurosci Methods (2016) 260:283-91. doi:10.1016/j.jneumeth.2015.11.012

22. Pang EW, Snead OC III. From structure to circuits: the contribution of MEG connectivity studies to functional neurosurgery. Front Neuroanat (2016) 10:67. doi:10.3389/fnana.2016.00067

23. Stam CJ. Use of magnetoencephalography (MEG) to study functional brain networks in neurodegenerative disorders. J Neurol Sci (2010) 289(1):128-34. doi:10.1016/j.jns.2009.08.028

24. Wilson TW, Heinrichs-Graham E, Proskovec AL, McDermott TJ. Neuroimaging with magnetoencephalography: a dynamic view of brain pathophysiology. Transl Res (2016) 175:17-36. doi:10.1016/j.trsl.2016. 01.007

25. Uhlhaas PJ, Liddle P, Linden D, Nobre AC, Singh KD, Gross J. Magnetoencephalography as a tool in psychiatric research: current status and perspective. Biol Psychiatry Cogn Neurosci Neuroimaging (2017). doi:10.1016/j.bpsc.2017.01.005

26. Brookes MJ, Woolrich M, Luckhoo H, Price D, Hale JR, Stephenson MC, et al. Investigating the electrophysiological basis of resting state networks using magnetoencephalography. Proc Natl Acad Sci U S A (2011) 108(40):16783-8. doi:10.1073/pnas.1112685108

27. Buckner RL, Andrews-Hanna JR, Schacter DL. The brain's default network anatomy, function, and relevance to disease. Ann N Y Acad Sci (2008) 1124:1-38. doi:10.1196/annals.1440.011

28. Deco G, Jirsa VK, McIntosh AR. Emerging concepts for the dynamical organization of resting-state activity in the brain. Nat Rev Neurosci (2011) 12(1):43-56. doi:10.1038/nrn2961

29. Shehzad Z, Kelly AM, Reiss PT, Gee DG, Gotimer K, Uddin LQ, et al. The resting brain: unconstrained yet reliable. Cereb Cortex (2009) 19(10):2209-29. doi:10.1093/cercor/bhn256

30. Beckmann CF, DeLuca M, Devlin JT, Smith SM. Investigations into resting-state connectivity using independent component analysis. Philos Trans R Soc Lond B Biol Sci (2005) 360(1457):1001-13. doi:10.1098/rstb. 2005.1634

31. van den Heuvel MP, Mandl RC, Kahn RS, Hulshoff Pol HE. Functionally linked resting-state networks reflect the underlying structural connectivity architecture of the human brain. Hum Brain Mapp (2009) 30(10):3127-41. doi:10.1002/hbm.20737

32. Damoiseaux JS, Rombouts SA, Barkhof F, Scheltens P, Stam CJ, Smith SM, et al. Consistent resting-state networks across healthy subjects. Proc Natl Acad Sci U S A (2006) 103(37):13848-53. doi:10.1073/pnas.0601417103

33. Biswal B, Yetkin FZ, Haughton VM, Hyde JS. Functional connectivity in the motor cortex of resting human brain using echo-planar MRI. Magn Reson Med (1995) 34(4):537-41. doi:10.1002/mrm.1910340409

34. Mulders PC, van Eijndhoven PF, Schene AH, Beckmann CF, Tendolkar I. Resting-state functional connectivity in major depressive disorder: a review. Neurosci Biobehav Rev (2015) 56:330-44. doi:10.1016/j.neubiorev.2015. 07.014

35. Fox MD, Raichle ME. Spontaneous fluctuations in brain activity observed with functional magnetic resonance imaging. Nat Rev Neurosci (2007) 8(9):700-11. doi:10.1038/nrn2201
36. Ongür D, Lundy M, Greenhouse I, Shinn AK, Menon V, Cohen BM, et al. Default mode network abnormalities in bipolar disorder and schizophrenia. Psychiatry Res (2010) 183(1):59-68. doi:10.1016/j.pscychresns.2010. 04.008

37. Ongür D, Prescot AP, Jensen JE, Rouse ED, Cohen BM, Renshaw PF, et al. $\mathrm{T}_{2}$ relaxation time abnormalities in bipolar disorder and schizophrenia. Magn Reson Med (2010) 63(1):1-8. doi:10.1002/mrm.22148

38. Allen EA, Damaraju E, Plis SM, Erhardt EB, Eichele T, Calhoun VD. Tracking whole-brain connectivity dynamics in the resting state. Cereb Cortex (2014) 24(3):663-76. doi:10.1093/cercor/bhs352

39. van den Heuvel MP, Hulshoff Pol HE. Exploring the brain network: a review on resting-state fMRI functional connectivity. Eur Neuropsychopharmacol (2010) 20(8):519-34. doi:10.1016/j.euroneuro.2010.03.008

40. Buckner RL. The brain's default network: origins and implications for the study of psychosis. Dialogues Clin Neurosci (2013) 15(3):351-8.

41. Karbasforoushan H, Woodward ND. Resting-state networks in schizophrenia. Curr Top Med Chem (2012) 12(21):2404-14. doi:10.2174/156802612 805289863

42. Vargas C, López-Jaramillo C, Vieta E. A systematic literature review of resting state network - functional MRI in bipolar disorder. J Affect Disord (2013) 150(3):727-35. doi:10.1016/j.jad.2013.05.083

43. Buzsáki G, Draguhn A. Neuronal oscillations in cortical networks. Science (2004) 304(5679):527-1929. doi:10.1126/science.1099745

44. Bullmore E, Sporns O. Complex brain networks: graph theoretical analysis of structural and functional systems. Nat Rev Neurosci (2009) 10(3):186-98. doi: $10.1038 / \mathrm{nrn} 2575$

45. Friston KJ. The disconnection hypothesis. Schizophr Res (1998) 30(2):115-25. doi:10.1016/S0920-9964(97)00140-0

46. Rubinov M, Sporns O. Complex network measures of brain connectivity: uses and interpretations. Neuroimage (2010) 52(3):1059-69. doi:10.1016/ j.neuroimage.2009.10.003

47. Hillebrand A, Barnes GR, Bosboom JL, Berendse HW, Stam CJ. Frequencydependent functional connectivity within resting-state networks: an atlas-based MEG beamformer solution. Neuroimage (2012) 59(4):3909-21. doi:10.1016/j.neuroimage.2011.11.005

48. Schoffelen JM, Gross J. Source connectivity analysis with MEG and EEG. Hum Brain Mapp (2009) 30(6):1857-65. doi:10.1002/hbm.20745

49. Wang HE, Bénar CG, Quilichini PP, Friston KJ, Jirsa VK, Bernard C. A systematic framework for functional connectivity measures. Front Neurosci (2014) 8:405. doi:10.3389/fnins.2014.00405

50. Knösche TR, Tittgemeyer M. The role of long-range connectivity for the characterization of the functional-anatomical organization of the cortex. Front Syst Neurosci (2011) 5:58. doi:10.3389/fnsys.2011.00058

51. Sakkalis V. Review of advanced techniques for the estimation of brain connectivity measured with EEG/MEG. Comput Biol Med (2011) 41(12):1110-7. doi:10.1016/j.compbiomed.2011.06.020

52. Stam CJ, Nolte G, Daffertshofer A. Phase lag index: assessment of functional connectivity from multi channel EEG and MEG with diminished bias from common sources. Hum Brain Mapp (2007) 28(11):1178-93. doi:10.1002/ hbm. 20346

53. Honey CJ, Kötter R, Breakspear M, Sporns O. Network structure of cerebral cortex shapes functional connectivity on multiple time scales. Proc Natl Acad Sci U S A (2007) 104(24):10240-5. doi:10.1073/pnas.0701519104

54. Damoiseaux JS, Greicius MD. Greater than the sum of its parts: a review of studies combining structural connectivity and resting-state functional connectivity. Brain Struct Funct (2009) 213(6):525-33. doi:10.1007/s00429009-0208-6

55. Greicius MD, Supekar K, Menon V, Dougherty RF. Resting-state functional connectivity reflects structural connectivity in the default mode network. Cereb Cortex (2009) 19(1):72-8. doi:10.1093/cercor/bhn059

56. Honey CJ, Sporns O, Cammoun L, Gigandet X, Thiran JP, Meuli R, et al. "Predicting human resting-state functional connectivity from structural connectivity. Proc Natl Acad Sci U S A (2009) 106(6):2035-40. doi:10.1073/ pnas.0811168106

57. Astolfi L, Cincotti F, Mattia D, Salinari S, Babiloni C, Basilisco A, et al. Estimation of the effective and functional human cortical connectivity with structural equation modeling and directed transfer function applied to high-resolution EEG. Magn Reson Imaging (2004) 22(10):1457-70. doi:10.1016/j.mri.2004.10.006 
58. Mathalon DH, Sohal VS. Neural oscillations and synchrony in brain dysfunction and neuropsychiatric disorders: it's about time. JAMA Psychiatry (2015) 72(8):840-4. doi:10.1001/jamapsychiatry.2015.0483

59. Girard P, Hupé JM, Bullier J. Feedforward and feedback connections between areas V1 and V2 of the monkey have similar rapid conduction velocities. J Neurophysiol (2001) 85(3):1328-31.

60. Uhlhaas PJ, Singer W. High-frequency oscillations and the neurobiology of schizophrenia. Dialogues Clin Neurosci (2013) 15(3):301-13.

61. Uhlhaas PJ, Haenschel C, Nikolić D, Singer W. The role of oscillations and synchrony in cortical networks and their putative relevance for the pathophysiology of schizophrenia. Schizophr Bull (2008) 34(5):927-43. doi:10.1093/schbul/sbn062

62. Spellman TJ, Gordon JA. Synchrony in schizophrenia: a window into circuit-level pathophysiology. Curr Opin Neurobiol (2015) 30:17-23. doi:10.1016/j.conb.2014.08.009

63. Buzsáki G, Watson BO. Brain rhythms and neural syntax: implications for efficient coding of cognitive content and neuropsychiatric disease. Dialogues Clin Neurosci (2012) 14(4):345-67.

64. Marzetti L, Del Gratta C, Nolte G. Understanding brain connectivity from EEG data by identifying systems composed of interacting sources. Neuroimage (2008) 42(1):87-98. doi:10.1016/j.neuroimage.2008.04.250

65. Nolte G, Bai O, Wheaton L, Mari Z, Vorbach S, Hallett M. Identifying true brain interaction from EEG data using the imaginary part of coherency. Clin Neurophysiol (2004) 115:2292-307. doi:10.1016/j.clinph.2004.04.029

66. Vinck M, Oostenveld R, van Wingerden M, Battaglia F, Pennartz CM. An improved index of phase-synchronization for electrophysiological data in the presence of volume-conduction, noise and sample-size bias. Neuroimage (2011) 55(4):1548-65. doi:10.1016/j.neuroimage.2011.01.055

67. Uhlhaas PJ. Dysconnectivity, large-scale networks and neuronal dynamics in schizophrenia. Curr Opin Neurobiol (2013) 23(2):283-90. doi:10.1016/ j.conb.2012.11.004

68. American Psychiatric Association. Diagnostic and Statistical Manual of Mental Disorders. 5th ed. Washington, DC: American Psychiatric Association (2013).

69. Satistics Canada. Canadian Community Health Survey (CCHS) - Mental Health User Guide. Ottawa, ON: Statistics Canada (2013).

70. Kessler RC, Berglund P, Demler O, Jin R, Koretz D, Merikangas KR, et al. The epidemiology of major depressive disorder: results from the National Comorbidity Survey Replication (NCS-R). JAMA (2003) 289(23):3095. doi:10.1001/jama.289.23.3095

71. World Health Organization. Fact Sheet: Mental Disorders. Geneva: World Health Organization (2016).

72. Anand A, Li Y, Wang Y, Wu J, Gao S, Bukhari L, et al. Activity and connectivity of brain mood regulating circuit in depression: a functional magnetic resonance study. Biol Psychiatry (2005) 57(10):1079-88. doi:10.1016/ j.biopsych.2005.02.021

73. Silbersweig D. Default mode subnetworks, connectivity, depression and its treatment: toward brain-based biomarker development. Biol Psychiatry (2013) 74:5-6. doi:10.1016/j.biopsych.2013.05.011

74. Vasic N, Walter H, Sambataro F, Wolf RC, Austin M-P, Mitchell P, et al. Aberrant functional connectivity of dorsolateral prefrontal and cingulate networks in patients with major depression during working memory processing. Psychol Med (2009) 39(6):977. doi:10.1017/S0033291708004443

75. Iwabuchi SJ, Krishnadas R, Li C, Auer DP, Radua J, Palaniyappan L. Localized connectivity in depression: a meta-analysis of resting state functional imaging studies. Neurosci Biobehav Rev (2015) 51:77-86. doi:10.1016/ j.neubiorev.2015.01.006

76. Kaiser RH, Andrews-Hanna JR, Wager TD, Pizzagalli DA. Large-scale network dysfunction in major depressive disorder a meta-analysis of resting-state functional connectivity. JAMA Psychiatry (2015) 72(6):603-11. doi:10.1001/jamapsychiatry.2015.0071

77. Gong Q, He Y. Depression, neuroimaging and connectomics: a selective overview. Biol Psychiatry (2015) 77(3):223-35. doi:10.1016/j.biopsych.2014. 08.009

78. Berman MG, Peltier S, Nee DE, Kross E, Deldin PJ, Jonides J. Depression, rumination and the default network. Soc Cogn Affect Neurosci (2011) 6(5):548-55. doi:10.1093/scan/nsq080

79. Greicius MD, Flores BH, Menon V, Glover GH, Solvason HB, Kenna H, et al. Resting-state functional connectivity in major depression: abnormally increased contributions from subgenual cingulate cortex and thalamus. Biol Psychiatry (2007) 62(5):429-37. doi:10.1016/j.biopsych.2006.09.020

80. Whitfield-Gabrieli S, Ford JM. Default mode network activity and connectivity in psychopathology. Annu Rev Clin Psychol (2012) 8(1):49-76. doi:10.1146/annurev-clinpsy-032511-143049

81. Fox MD, Buckner RL, White MP, Greicius MD, Pascual-Leone A. Efficacy of transcranial magnetic stimulation targets for depression is related to intrinsic functional connectivity with the subgenual cingulate. Biol Psychiatry (2012) 72(7):595-603. doi:10.1016/j.biopsych.2012.04.028

82. Veer IM, Beckmann CF, van Tol MJ, Ferrarini L, Milles J, Veltman DJ, et al. Whole brain resting-state analysis reveals decreased functional connectivity in major depression. Front Syst Neurosci (2010) 4:41. doi:10.3389/ fnsys. 2010.00041

83. Zeng LL, Shen H, Liu L, Wang L, Li B, Fang P, et al. Identifying major depression using whole-brain functional connectivity: a multivariate pattern analysis. Brain (2012) 135(Pt 5):1498-507. doi:10.1093/brain/aws059

84. Dannlowski U, Ohrmann P, Konrad C, Domschke K, Bauer J, Kugel H, et al. Reduced amygdala-prefrontal coupling in major depression: association with maoa genotype and illness severity. Int J Neuropsychopharmacol (2009) 12(1):11-22. doi:10.1017/S1461145708008973

85. He H, Yu Q, Du Y, Vergara V, Victor TA, Drevets WC, et al. Resting-state functional network connectivity in prefrontal regions differs between unmedicated patients with bipolar and major depressive disorders. J Affect Disord (2016) 190:483-93. doi:10.1016/j.jad.2015.10.042

86. Siegle GJ, Thompson W, Carter CS, Steinhauer SR, Thase ME. Increased amygdala and decreased dorsolateral prefrontal BOLD responses in unipolar depression: related and independent features. Biol Psychiatry (2007) 61(2):198-209. doi:10.1016/j.biopsych.2006.05.048

87. Avery JA, Drevets WC, Moseman SE, Bodurka J, Barcalow JC, Simmons WK. Major depressive disorder is associated with abnormal interoceptive activity and functional connectivity in the Insula. Biol Psychiatry (2014) 76(3):258-66. doi:10.1016/j.biopsych.2013.11.027

88. Drevets WC. Orbitofrontal cortex function and structure in depression. Ann N Y Acad Sci (2007) 1121:499-527. doi:10.1196/annals.1401.029

89. Koo PC, Thome J, Berger C, Foley P, Hoeppner J. Current source density analysis of resting state EEG in depression: a review. J Neural Transm (Vienna) (2015) 124:109-18. doi:10.1007/s00702-015-1432-2

90. Leuchter AF, Hunter AM, Krantz DE, Cook IA. Rhythms and blues: modulation of oscillatory synchrony and the mechanism of action of antidepressant treatments. Ann N Y Acad Sci (2015) 1344:78-91. doi:10.1111/nyas. 12742

91. Leuchter AF, Cook IA, Hunter AM, Cai C, Horvath S. Resting-state quantitative electroencephalography reveals increased neurophysiologic connectivity in depression. PLoS One (2012) 7(2):e32508. doi:10.1371/ journal.pone. 0032508

92. Olbrich S, Tränkner A, Chittka T, Hegerl U, Schönknecht P. Functional connectivity in major depression: increased phase synchronization between frontal cortical EEG-source estimates. Psychiatry Res (2014) 222(1):91-9. doi:10.1016/j.pscychresns.2014.02.010

93. Schulman JJ, Cancro R, Lowe S, Lu F, Walton KD, Llinás RR. Imaging of thalamocortical dysrhythmia in neuropsychiatry. Front Hum Neurosci (2011) 5:69. doi:10.3389/fnhum.2011.00069

94. Fingelkurts AA, Fingelkurts AA, Rytsälä H, Suominen K, Isometsä E, Kähkönen S. Impaired functional connectivity at EEG alpha and theta frequency bands in major depression. Hum Brain Mapp (2007) 28(3):247-61. doi: $10.1002 / \mathrm{hbm} .20275$

95. Keeser D, Karch S, Davis JR, Surmeli T, Engelbregt H, Länger A, et al. Changes of resting-state EEG and functional connectivity in the sensor and source space of patients with major depression. Klinische Neurophysiologie (2013) 44(1):142. doi:10.1055/s-0033-1337283

96. Lee TW, Wu YT, Yu YW, Chen MC, Chen TJ. The implication of functional connectivity strength in predicting treatment response of major depressive disorder: a resting EEG study. Psychiatry Res (2011) 194(3):372-7. doi:10.1016/j.pscychresns.2011.02.009

97. Mayberg HS, Lozano AM, Voon V, McNeely HE, Seminowicz D, Hamani C, et al. Deep brain stimulation for treatment-resistant depression. Neuron (2005) 45(5):651-60. doi:10.1016/j.neuron.2005.02.014

98. Johansen-Berg H, Gutman DA, Behrens TEJ, Matthews PM, Rushworth MFS, Katz E, et al. Anatomical connectivity of the subgenual cingulate region 
targeted with deep brain stimulation for treatment-resistant depression. Cereb Cortex (2008) 18(6):1374-83. doi:10.1093/cercor/bhm167

99. Lozano AM, Giacobbe P, Hamani C, Rizvi SJ, Kennedy SH, Kolivakis TT, et al. A multicenter pilot study of subcallosal cingulate area deep brain stimulation for treatment-resistant depression. J Neurosurg (2012) 116(2):315-22. doi:10.3171/2011.10.JNS102122

100. Kennedy SH, Milev R, Giacobbe P, Ramasubbu R, Lam RW, Parikh SV, et al. Canadian network for mood and anxiety treatments (CANMAT) clinical guidelines for the management of major depressive disorder in adults: IV. Neurostimulation therapies. J Affect Disord (2009) 117(Suppl 1):S44-53. doi:10.1016/j.jad.2009.06.039

101. Kennedy SH, Giacobbe P, Rizvi SJ, Placenza FM, Nishikawa Y, Mayberg HS, et al. Deep brain stimulation for treatment-resistant depression: follow-up after 3 to 6 years. Am J Psychiatry (2011) 168(5):502-10. doi:10.1176/appi. ajp.2010.10081187

102. PuigdemontD, Pérez-Egea R, Portella MJ, MoletJ, de Diego-Adeliño J, Gironell A, et al. Deep brain stimulation of the subcallosal cingulate gyrus: further evidence in treatment-resistant major depression. Int J Neuropsychopharmacol (2012) 15(1):121-33. doi:10.1017/S1461145711001088

103. Morishita T, Fayad SM, Higuchi MA, Nestor KA, Foote KD. Deep brain stimulation for treatment-resistant depression: systematic review of clinical outcomes. Neurotherapeutics (2014) 11(3):475-84. doi:10.1007/ s13311-014-0282-1

104. Merikangas KR, Akiskal HS, Angst J, Greenberg PE, Hirschfeld RM, Petukhova $\mathrm{M}$, et al. Lifetime and 12-month prevalence of bipolar spectrum disorder in the National Comorbidity Survey Replication. Arch Gen Psychiatry (2007) 64(5):543-52. doi:10.1001/archpsyc. 64.5.543

105. Almeida JR, Mechelli A, Hassel S, Versace A, Kupfer DJ, Phillips ML. Abnormally increased effective connectivity between parahippocampal gyrus and ventromedial prefrontal regions during emotion labeling in bipolar disorder. Psychiatry Res (2009) 174(3):195-201. doi:10.1016/ j.pscychresns.2009.04.015

106. Versace A, Thompson WK, Zhou D, Almeida JR, Hassel S, Klein CR, et al. Abnormal left and right amygdala-orbitofrontal cortical functional connectivity to emotional faces: state versus trait vulnerability markers of depression in bipolar disorder. Biol Psychiatry (2010) 67(5):422-31. doi:10.1016/ j.biopsych.2009.11.025

107. Wang F, Kalmar JH, He Y, Jackowski M, Chepenik LG, Edmiston EE, et al. Functional and structural connectivity between the perigenual anterior cingulate and amygdala in bipolar disorder. Biol Psychiatry (2009) 66(5):516-21. doi:10.1016/j.biopsych.2009.03.023

108. Chase HW, Phillips ML. Elucidating neural network functional connectivity abnormalities in bipolar disorder: toward a harmonized methodological approach. Biol Psychiatry Cogn Neurosci Neuroimaging (2016) 1(3):288-98. doi:10.1016/j.bpsc.2015.12.006

109. Piguet C, Fodoulian L, Aubry JM, Vuilleumier P, Houenou J. Bipolar disorder: functional neuroimaging markers in relatives. Neurosci Biobehav Rev (2015) 57:284-96. doi:10.1016/j.neubiorev.2015.08.015

110. Magioncalda P, Martino M, Conio B, Escelsior A, Piaggio N, Presta A, et al. Functional connectivity and neuronal variability of resting state activity in bipolar disorder-reduction and decoupling in anterior cortical midline structures. Hum Brain Mapp (2015) 36(2):666-82. doi:10.1002/ hbm. 22655

111. Reinke B, Ven Vv, Matura S, Linden DE, Oertel-Knöchel V. Altered intrinsic functional connectivity in language-related brain regions in association with verbal memory performance in euthymic bipolar patients. Brain Sci (2013) 3(3):1357-73. doi:10.3390/brainsci3031357

112. Martino M, Magioncalda P, Saiote C, Conio B, Escelsior A, Rocchi G, et al. Abnormal functional-structural cingulum connectivity in mania: combined functional magnetic resonance imaging-diffusion tensor imaging investigation in different phases of bipolar disorder. Acta Psychiatr Scand (2016) 134(4):339-49. doi:10.1111/acps.12596

113. Calhoun VD, Sui J, Kiehl K, Turner J, Allen E, Pearlson G. Exploring the psychosis functional connectome: aberrant intrinsic networks in schizophrenia and bipolar disorder. Front Psychiatry (2012) 2:75. doi:10.3389/ fpsyt.2011.00075

114. Chai XJ, Whitfield-Gabrieli S, Shinn AK, Gabrieli JD, Nieto Castañón A, McCarthy JM, et al. Abnormal medial prefrontal cortex resting-state connectivityin bipolar disorder and schizophrenia. Neuropsychopharmacology (2011) 36(10):2009-17. doi:10.1038/npp.2011.88

115. Rashid B, Damaraju E, Pearlson GD, Calhoun VD. Dynamic connectivity states estimated from resting fMRI identify differences among schizophrenia, bipolar disorder, and healthy control subjects. Front Hum Neurosci (2014) 8:897. doi:10.3389/fnhum.2014.00897

116. Houenou J, d'Albis MA, Vederine FE, Henry C, Leboyer M, Wessa M. Neuroimaging biomarkers in bipolar disorder. Front Biosci (2012) 4:593-606. doi: $10.2741 / \mathrm{e} 402$

117. Phillips ML, Swartz HA. A critical appraisal of neuroimaging studies of bipolar disorder: toward a new conceptualization of underlying neural circuitry and a road map for future research. Am J Psychiatry (2014) 171(8):829-43. doi:10.1176/appi.ajp.2014.13081008

118. Strakowski SM, Adler CM, Almeida J, Altshuler LL, Blumberg HP, Chang $\mathrm{KD}$, et al. The functional neuroanatomy of bipolar disorder: a consensus model. Bipolar Disord (2012) 14(4):313-25. doi:10.1111/j.1399-5618.2012. 01022.x

119. Liu H, Tang Y, Womer F, Fan G, Lu T, Driesen N, et al. Differentiating patterns of amygdala-frontal functional connectivity in schizophrenia and bipolar disorder. Schizophr Bull (2014) 40(2):469-77. doi:10.1093/schbul/ sbt044

120. Anticevic A, Brumbaugh MS, Winkler AM, Lombardo LE, Barrett J, Corlett PR, et al. Global prefrontal and fronto-amygdala dysconnectivity in bipolar I disorder with psychosis history. Biol Psychiatry (2013) 73(6):565-73. doi:10.1016/j.biopsych.2012.07.031

121. Nusslock R, Harmon-Jones E, Alloy LB, Urosevic S, Goldstein K, Abramson LY. Elevated left mid-frontal cortical activity prospectively predicts conversion to bipolar I disorder. J Abnorm Psychol (2012) 121(3):592-601. doi:10.1037/a0028973

122. Howells FM, Ives-Deliperi VL, Horn NR, Stein DJ. Mindfulness based cognitive therapy improves frontal control in bipolar disorder: a pilot EEG study. BMC Psychiatry (2012) 12(1):15. doi:10.1186/1471-244X-12-15

123. Kam JW, Bolbecker AR, O’Donnell BF, Hetrick WP, Brenner CA. Resting state EEG power and coherence abnormalities in bipolar disorder and schizophrenia. J Psychiatr Res (2013) 47(12):1893-901. doi:10.1016/j. jpsychires.2013.09.009

124. Kim DJ, Bolbecker AR, Howell J, Rass O, Sporns O, Hetrick WP, et al. Disturbed resting state EEG synchronization in bipolar disorder: a graph-theoretic analysis. Neuroimage Clin (2013) 2(1):414-23. doi:10.1016/j.nicl.2013. 03.007

125. Yener GG, Başar E. Brain oscillations as biomarkers in neuropsychiatric disorders: following an interactive panel discussion and synopsis. Suppl Clin Neurophysiol (2013) 62:343-63. doi:10.1016/B978-0-7020-5307-8. 00016-8

126. Perry G, Singh KD. Localizing evoked and induced responses to faces using magnetoencephalography. Eur J Neurosci (2014) 39(9):1517-27. doi:10.1111/ ejn. 12520

127. Williams MA, Sachdev PS. Magnetoencephalography in neuropsychiatry: ready for application? Curr Opin Psychiatry (2010) 23(3):273-7. doi:10.1097/ YCO.0b013e328338621d

128. Jiang H, Popov T, Jylänki P, Bi K, Yao Z, Lu Q, et al. Predictability of depression severity based on posterior alpha oscillations. Neurophysiol Clin (2016) 127(4):2108-14. doi:10.1016/j.clinph.2015.12.018

129. Li CT, Chen LF, Tu PC, Wang SJ, Chen MH, Su TP, et al. Impaired prefronto-thalamic functional connectivity as a key feature of treatment-resistant depression: a combined MEG, PET and rTMS study. PLoS One (2013) 8(8):e70089. doi:10.1371/journal.pone.0070089

130. Zotev V, Yuan H, Misaki M, Phillips R, Young KD, Feldner MT, et al. Correlation between amygdala BOLD activity and frontal EEG asymmetry during real-time fMRI neurofeedback training in patients with depression. Neuroimage Clin (2016) 11:224-38. doi:10.1016/j.nicl.2016.02.003

131. Brzezicka A, Kamiński J, Kamińska OK, Wołyńczyk-Gmaj D, Sedek G. Frontal EEG alpha band asymmetry as a predictor of reasoning deficiency in depressed people. Cogn Emot (2016). 1-11. doi:10.1080/02699931.2016. 1170669

132. Nugent AC, Robinson SE, Coppola R, Furey ML, Zarate CA Jr. Group differences in MEG-ICA derived resting state networks: application to major depressive disorder. Neuroimage (2015) 118:1-12. doi:10.1016/ j.neuroimage.2015.05.051 
133. Nugent AC, Robinson SE, Coppola R, Zarate CA Jr. Preliminary differences in resting state MEG functional connectivity pre- and post-ketamine in major depressive disorder. Psychiatry Res (2016) 254:56-66. doi:10.1016/j. pscychresns.2016.06.006

134. Pathak Y, Salami O, Baillet S, Li Z, Butson CR. Longitudinal changes in depressive circuitry in response to neuromodulation therapy. Front Neural Circuits (2016) 10:50. doi:10.3389/fncir.2016.00050

135. Drevets WC, Savitz J, Trimble M. The subgenual anterior cingulate cortex in mood disorders. CNS Spectr (2008) 13(8):663-81. doi:10.1017/ S1092852900013754

136. Jaworska N, Yücel K, Courtright A, MacMaster FP, Sembo M, MacQueen G. Subgenual anterior cingulate cortex and hippocampal volumes in depressed youth: the role of comorbidity and age. J Affect Disord (2016) 190:726-32. doi:10.1016/j.jad.2015.10.064

137. Lu Q, Li H, Luo G, Wang Y, Tang H, Han L, et al. Impaired prefrontal-amygdala effective connectivity is responsible for the dysfunction of emotion process in major depressive disorder: a dynamic causal modeling study on MEG. Neurosci Lett (2012) 523(2):125-30. doi:10.1016/j.neulet.2012.06.058

138. Lu Q, Wang Y, Luo G, Li H, Yao Z. Dynamic connectivity laterality of the amygdala under negative stimulus in depression: a MEG study. Neurosci Lett (2013) 547:42-7. doi:10.1016/j.neulet.2013.05.002

139. Lu Q, Bi K, Liu C, Luo G, Tang H, Yao Z. Predicting depression based on dynamic regional connectivity: a windowed granger causality analysis of MEG recordings. Brain Res (2013) 1535:52-60. doi:10.1016/j.brainres.2013.08.033

140. Salvadore G, Cornwell BR, Sambataro F, Latov D, Colon-Rosario V, Carver F, et al. Anterior cingulate desynchronization and functional connectivity with the amygdala during a working memory task predict rapid antidepressant response to ketamine. Neuropsychopharmacology (2010) 35(7):1415-22. doi:10.1038/npp.2010.24

141. Al-Timemy AH, Fernandez A, Escudero J. Spectral analysis of resting state magnetoencephalogram activity in patients with bipolar disorder. Conf Proc IEEE Eng Med Biol Soc (2014) 2014:2197-200. doi:10.1109/ EMBC.2014.6944054

142. Chen SS, Tu PC, Su TP, Hsieh JC, Lin YC, Chen LF. Impaired frontal synchronization of spontaneous magnetoencephalographic activity in patients with bipolar disorder. Neurosci Lett (2008) 445(2):174-8. doi:10.1016/ j.neulet.2008.08.080

143. Arnhold J, Grassberger P, Lehnertz K, Elger CE. A robust method for detecting interdependences: application to intracranially recorded EEG. Physica D (1999) 134:419-30. doi:10.1016/S0167-2789(99)00140-2

144. Lee PS, Chen YS, Hsieh JC, Su TP, Chen LF. Distinct neuronal oscillatory responses between patients with bipolar and unipolar disorders: a magnetoencephalographic study. J Affect Disord (2010) 123(1):270-5. doi:10.1016/ j.jad.2009.08.020

145. Rich BA, Holroyd T, Carver FW, Onelio LM, Mendoza JK, Cornwell BR, et al. A preliminary study of the neural mechanisms of frustration in pediatric bipolar disorder using magnetoencephalography. Depress Anxiety (2010) 27(3):276-86. doi:10.1002/da.20649

146. van Diessen E, Numan T, van Dellen E, van der Kooi AW, Boersma M, Hofman D, et al. Opportunities and methodological challenges in EEG and MEG resting state functional brain network research. Neurophysiol Clin (2015) 126(8):1468-81. doi:10.1016/j.clinph.2014.11.018

147. Colclough GL, Brookes MJ, Smith SM, Woolrich MW. A symmetric multivariate leakage correction for MEG connectomes. Neuroimage (2015) 117:439-48. doi:10.1016/j.neuroimage.2015.03.071

148. Hillebrand A, Tewarie P, van Dellen E, Yu M, Carbo EW, Douw L, et al. Direction of information flow in large-scale resting-state networks is frequency-dependent. Proc Natl Acad Sci U S A (2016) 113(14):3867-72. doi:10.1073/pnas. 1515657113

149. O’Neill GC, Barratt EL, Hunt BA, Tewarie PK, Brookes MJ. Measuring electrophysiological connectivity by power envelope correlation: a technical review on MEG methods. Phys Med Biol (2015) 60:R271-95. doi:10.1088/0031-9155/60/21/R271

150. Hipp JF, Hawellek DJ, Corbetta M, Siegel M, Engel AK. Large-scale cortical correlation structure of spontaneous oscillatory activity. Nat Neurosci (2012) 15(6):884-90. doi:10.1038/nn.3101

151. Brookes MJ, Woolrich MW, Barnes GR. Measuring functional connectivity in MEG: a multivariate approach insensitive to linear source leakage. Neuroimage (2012) 63(2):910-20. doi:10.1016/j.neuroimage.2012.03.048
152. Hinkley LB, Vinogradov S, Guggisberg AG, Fisher M, Findlay AM, Nagarajan SS. Clinical symptoms and alpha band resting-state functional connectivity imaging in patients with schizophrenia: implications for novel approaches to treatment. Biol Psychiatry (2011) 70(12):1134-42. doi:10.1016/ j.biopsych.2011.06.029

153. Bowyer SM, Gjini K, Zhu X, Kim L, Moran JE, Rizvi SU, et al. Potential biomarkers of schizophrenia from MEG resting-state functional connectivity networks: preliminary data. J Behav Brain Sci (2015) 5(5):1-11. doi:10.4236/ jbbs.2015.51001

154. Baillet S, Garnero L, Marin G, Hugonin JP. Combined MEG and EEG source imaging by minimization of mutual information. IEEE Trans Biomed Eng (1999) 46(5):522-34. doi:10.1109/10.759053

155. Hincapié AS, Kujala J, Mattout J, Daligault S, Delpuech C, Mery D, et al. MEG connectivity and power detections with minimum norm estimates require different regularization parameters. Comput Intell Neurosci (2016) 2016:1-11. doi:10.1155/2016/3979547

156. Colclough GL, Woolrich MW, Tewarie PK, Brookes MJ, Quinn AJ, Smith SM. How reliable are MEG resting-state connectivity metrics? Neuroimage (2016) 138:284-93. doi:10.1016/j.neuroimage.2016.05.070

157. Garcés P, Martín-Buro MC, Maestú F. Quantifying the test-retest reliability of magnetoencephalography resting-state functional connectivity. Brain Connect (2016) 6(6):448-60. doi:10.1089/brain.2015.0416

158. Wens V, Bourguignon M, Goldman S, Marty B, Op de Beeck M, Clumeck $\mathrm{C}$, et al. Inter- and intra-subject variability of neuromagnetic resting state networks. Brain Topogr (2014) 27(5):620-34. doi:10.1007/s10548-0140364-8

159. Fraschini M, Demuru M, Crobe A, Marrosu F, Stam CJ, Hillebrand A. The effect of epoch length on estimated EEG functional connectivity and brain network organisation. J Neural Eng (2016) 13(3):36015. doi:10.1088/1741-2560/13/3/036015

160. Fucetola R, Seidman LJ, Kremen WS, Faraone SV, Goldstein JM, Tsuang MT. Age and neuropsychologic function in schizophrenia: a decline in executive abilities beyond that observed in healthy volunteers. Biol Psychiatry (2000) 48(2):137-46. doi:10.1016/S0006-3223(00)00240-7

161. Tamm L, Menon V, Reiss AL. Maturation of brain function associated with response inhibition. J Am Acad Child Adolesc Psychiatry (2002) 41(10):12318. doi:10.1097/00004583-200210000-00013

162. Paus T, Keshavan M, Giedd JN. Why do many psychiatric disorders emerge during adolescence? Nat Rev Neurosci (2010) 9(12):947. doi:10.1038/nrn2513

163. Giedd JN, Blumenthal J, Jeffries NO, Castellanos FX, Liu H, Zijdenbos A et al. Brain development during childhood and adolescence: a longitudinal MRI study. Nat Neurosci (1999) 2(10):861-3. doi:10.1038/13158

164. Kwon H, Reiss AL, Menon V. Neural basis of protracted developmental changes in visuo-spatial working memory. Proc Natl Acad Sci U S A (2002) 99(20):13336-41. doi:10.1073/pnas.162486399

165. Adleman NE, Menon V, Blasey CM, White CD, Warsofsky IS, Glover $\mathrm{GH}$, et al. A developmental fMRI study of the Stroop Color-Word Task. Neuroimage (2002) 16(1):61-75. doi:10.1006/nimg.2001.1046

166. Clemmensen L, Vernal DL, Steinhausen HC, Helgeland MI, Torgersen S, Jobe $\mathrm{TH}$, et al. A systematic review of the long-term outcome of early onset schizophrenia. BMC Psychiatry (2012) 12(1):150. doi:10.1186/1471-244X-12-150

167. Strober M, Morrell W, Burroughs J, Lampert C, Danforth H, Freeman R. A family study of bipolar I disorder in adolescence: early onset of symptoms linked to increased familial loading and lithium resistance. J Affect Disord (1988) 15(3):255-68. doi:10.1016/0165-0327(88)90023-7

168. Perlis RH, Miyahara S, Marangell LB, Wisniewski SR, Ostacher M, DelBello MP, et al. Long-term implications of early onset in bipolar disorder: data from the first 1000 participants in the systematic treatment enhancement program for bipolar disorder (STEP-BD). Biol Psychiatry (2004) 55(9):875-81. doi:10.1016/j.biopsych.2004.01.022

169. Carlson GA. Phenomenology and outcome of subjects with early- and adult-onset psychotic mania. Am JPsychiatry (2000) 157(2):213-9. doi:10.1176/appi.ajp.157.2.213

170. Bijanki KR, Hodis B, Magnotta VA, Zeien E, Andreasen NC. Effects of age on white matter integrity and negative symptoms in schizophrenia. Schizophr Res (2015) 161(1):29-35. doi:10.1016/j.schres.2014.05.031

171. McCabe C, Mishor Z. Antidepressant medications reduce subcorticalcortical resting-state functional connectivity in healthy volunteers. Neuroimage (2011) 57(4):1317-23. doi:10.1016/j.neuroimage.2011.05.051 
172. Fusar-Poli P, Smieskova R, Kempton MJ, Ho BC, Andreasen NC, Borgwardt S. Progressive brain changes in schizophrenia related to antipsychotic treatment? A meta-analysis of longitudinal MRI studies. Neurosci Biobehav Rev (2013) 37(8):1680-91. doi:10.1016/j.neubiorev.2013. 06.001

173. Gudayol-Ferré E, Peró-Cebollero M, González-Garrido AA, Guàrdia-Olmos J. Changes in brain connectivity related to the treatment of depression measured through fMRI: a systematic review. Front Hum Neurosci (2015) 9:582. doi:10.3389/fnhum.2015.00582

174. Anand A, Li Y, Wang Y, Wu J, Gao S, Bukhari L, et al. Antidepressant effect on connectivity of the mood-regulating circuit: an fMRI study. Neuropsychopharmacology (2005) 30(7):1334. doi:10.1038/sj.npp.1300725

175. Nejad AB, Ebdrup BH, Glenthøj BY, Siebner HR. Brain connectivity studies in schizophrenia: unravelling the effects of antipsychotics. Curr Neuropharmacol (2012) 10(3):219-30. doi:10.2174/157015912803217305

176. Jääskeläinen E, Haapea M, Rautio N, Juola P, Penttilä M, Nordström T, et al. Twenty years of schizophrenia research in the Northern Finland Birth Cohort 1966: a systematic review. Schizophr Res Treatment (2015) 2015:524875. doi:10.1155/2015/524875

177. Smucny J, Olincy A, Tregellas JR. Nicotine restores functional connectivity of the ventral attention network in schizophrenia. Neuropharmacology (2016) 108:144-51. doi:10.1016/j.neuropharm.2016.04.015

178. Weiland BJ, Sabbineni A, Calhoun VD, Welsh RC, Hutchison KE. Reduced executive and default network functional connectivity in cigarette smokers. Hum Brain Mapp (2015) 36(3):872-82. doi:10.1002/hbm.22672

179. Rack-Gomer AL, Liau J, Liu TT. Caffeine reduces resting-state BOLD functional connectivity in the motor cortex. Neuroimage (2009) 46(1):56-63. doi:10.1016/j.neuroimage.2009.02.001

180. Zanchi D, Brody AL, Montandon ML, Kopel R, Emmert K, Preti MG, et al. Cigarette smoking leads to persistent and dose-dependent alterations of brain activity and connectivity in anterior insula and anterior cingulate. Addict Biol (2015) 20(6):1033-41. doi:10.1111/adb.12292

181. Jacobsen LK, D’Souza DC, Mencl WE, Pugh KR, Skudlarski P, Krystal JH. Nicotine effects on brain function and functional connectivity in schizophrenia. Biol Psychiatry (2004) 55(8):850-8. doi:10.1016/j.biopsych.2003. 12.023

182. Janes AC, Nickerson LD, Frederick Bde B, Kaufman MJ. Prefrontal and limbic resting state brain network functional connectivity differs between nicotine-dependent smokers and non-smoking controls. Drug Alcohol Depend (2012) 125(3):252-9. doi:10.1016/j.drugalcdep.2012.02.020

183. Tal O, Diwakar M, Wong CW, Olafsson V, Lee R, Huang MX, et al. Caffeineinduced global reductions in resting-state BOLD connectivity reflect widespread decreases in MEG connectivity. Front Hum Neurosci (2013) 7:63. doi:10.3389/fnhum.2013.00063

184. Reite M, Teale P, Rojas DC. Magnetoencephalography: applications in psychiatry. Biol Psychiatry (1999) 45(12):1553-63. doi:10.1016/ S0006-3223(99)00062-1
185. Casey BJ, Giedd JN, Thomas KM. Structural and functional brain development and its relation to cognitive development. Biol Psychol (2000) 54(1):241-57. doi:10.1016/S0301-0511(00)00058-2

186. Taylor MJ, Doesburg SM, Pang EW. Neuromagnetic vistas into typical and atypical development of frontal lobe functions. Front Hum Neurosci (2014) 8:453. doi:10.3389/fnhum.2014.00453

187. Kolb B, Mychasiuk R, Muhammad A, Li Y, Frost DO, Gibb R. Experience and the developing prefrontal cortex. Proc Natl Acad Sci U S A (2012) 109(Suppl 2):17186-93. doi:10.1073/pnas.1121251109

188. Carrion VG, Wong SS. Can traumatic stress alter the brain? Understanding the implications of early trauma on brain development and learning. J Adolesc Health (2012) 51(2):S23-8. doi:10.1016/j.jadohealth.2012.04.010

189. Grossmann T. The role of medial prefrontal cortex in early social cognition. Front Hum Neurosci (2013) 7:340. doi:10.3389/fnhum.2013.00340

190. Salomons TV, Dunlop K, Kennedy SH, Flint A, Geraci J, Giacobbe $\mathrm{P}$, et al. Resting-state cortico-thalamic-striatal connectivity predicts response to dorsomedial prefrontal rTMS in major depressive disorder. Neuropsychopharmacology (2014) 39(2):488-98. doi:10.1038/npp.2013.222

191. Downar J, Geraci J, Salomons TV, Dunlop K, Wheeler S, McAndrews MP, et al. Anhedonia and reward-circuit connectivity distinguish nonresponders from responders to dorsomedial prefrontal repetitive transcranial magnetic stimulation in major depression. Biol Psychiatry (2014) 76(3):176-85. doi:10.1016/j.biopsych.2013.10.026

192. Berlim MT, van den Eynde F, Tovar-Perdomo S, Daskalakis ZJ. Response, remission and drop-out rates following high-frequency repetitive transcranial magnetic stimulation (rTMS) for treating major depression: a systematic review and meta-analysis of randomized, double-blind and sham-controlled trials. Psychol Med (2014) 44(2):225-39. doi:10.1017/S0033291713000512

193. Tortella G, Selingardi PM, Moreno ML, Veronezi BP, Brunoni AR. Does non-invasive brain stimulation improve cognition in major depressive disorder? A systematic review. CNS Neurol Disord Drug Targets (2015) 13(10):1759-69. doi:10.2174/1871527313666141130224431

194. Cetin MS, Houck JM, Vergara VM, Miller RL, Calhoun V. Multimodal based classification of schizophrenia patients. Conf Proc IEEE Eng Med Biol Soc (2015) 2015:2629-32. doi:10.1109/EMBC.2015.7318931

Conflict of Interest Statement: The authors declare that the research was conducted in the absence of any commercial or financial relationships that could be construed as a potential conflict of interest.

Copyright (c) 2017 Alamian, Hincapié, Combrisson, Thiery, Martel, Althukov and Jerbi. This is an open-access article distributed under the terms of the Creative Commons Attribution License (CC BY). The use, distribution or reproduction in other forums is permitted, provided the original author(s) or licensor are credited and that the original publication in this journal is cited, in accordance with accepted academic practice. No use, distribution or reproduction is permitted which does not comply with these terms. 